\title{
Cbct evaluation of condylar changes in children with unilateral posterior crossbites with a functional shift
}

\author{
Lance Pittman \\ West Virginia University
}

Follow this and additional works at: https://researchrepository.wvu.edu/etd

\section{Recommended Citation}

Pittman, Lance, "Cbct evaluation of condylar changes in children with unilateral posterior crossbites with a functional shift" (2014). Graduate Theses, Dissertations, and Problem Reports. 573.

https://researchrepository.wvu.edu/etd/573

This Thesis is protected by copyright and/or related rights. It has been brought to you by the The Research Repository @ WVU with permission from the rights-holder(s). You are free to use this Thesis in any way that is permitted by the copyright and related rights legislation that applies to your use. For other uses you must obtain permission from the rights-holder(s) directly, unless additional rights are indicated by a Creative Commons license in the record and/ or on the work itself. This Thesis has been accepted for inclusion in WVU Graduate Theses, Dissertations, and Problem Reports collection by an authorized administrator of The Research Repository @ WVU. For more information, please contact researchrepository@mail.wvu.edu. 
CBCT Evaluation of Condylar Changes in Children with Unilateral Posterior Crossbites with a Functional Shift

Lance Pittman, D.D.S.

\author{
A Thesis Submitted to: \\ The School of Dentistry, Department of Orthodontics \\ At West Virginia University \\ In partial fulfillment of the requirements for the degree of \\ Master of Science in \\ Orthodontics
}

Richard Jurevic, D.D.S., Ph.D, chair

Peter Ngan, D.M.D.

Chris Martin, D.D.S., M.S.

Department of Orthodontics

Morgantown, WV 2014

Keywords: Temporomandibular Joint, TMJ, Cone Beam Computed Tomography, CBCT, Condyle

Copyright 2014 Lance Pittman, D.D.S. 


\section{Abstract \\ CBCT Evaluation of Condylar Changes in Children with Unilateral Posterior Crossbites with a Functional Shift}

\section{Lance Pittman, D.D.S.}

Introduction: Unilateral posterior crossbite with a functional shift is one of the most common early adolescent malocclusions. It is caused by a transversely deficient maxilla, relative to the mandible, and results when the mandible shifts to one side to so the teeth can maximally interdigitate. This shift is thought to cause the contralateral condyle to move anteriorly, inferiorly, and medially within the TMJ. Much attention has been given recently to the affects of this functional shift on the condyles. An attempt is being made to determine if pathological position of the condyles can cause condylar signs or symptoms similar to DJD or JCR, or if the position of the condyle is in an altered position within the TMJ.

Methodology: Sixty DICOM images were reviewed from the private database of Thomas Shipley D.M.D., M.S. of Peoria, AZ. Thirty one subjects were selected for the control group and twenty nine subjects were selected based on a unilateral posterior crossbite with a functional shift. Transverse dimensions were measured at the skeletal base and the dentoalveolar base. Molar inclinations, condylar angulations, and condylar anterior joint spaces, superior joint spaces, and posterior joint spaces were measured. ANOVA was used to compare different groups and matched pair was used to compare differences within the same patient. Pairwise correlation was used to determine reliability. Results: The dentoalveolar measurements concluded our crossbite group had a maxillomandibular difference of $-8.22 \mathrm{~mm} \pm 3.04$ and our control group had a difference of $-4.01 \pm 2.69$. There were no statistical differences between molar inclinations, condylar width or angulation, or any joint space measurements. $19 / 31$ of the control group, and 21/29 of the crossbite group had a radiographic sign of joint disease. Conclusion: Since there were no positional differences in the condyle between the control and crossbite groups, some sort of remodeling that occurs within the TMJ would likely have to occur and may be why many of the crossbite group had signs of joint disease. 


\section{Dedications}

I dedicate this thesis to my wife Alyssa, for her continued love and support. Without you this would not have been possible.

I would like to thank my parents Larry and Linda Pittman, for their love and help, and teaching me to believe that anything is possible through hard work.

I would like to thank my brother and sister, Matt and Meghan, for all of your support over the years. I look forward to spending much more time with you.

I would like to thank my Lord and Savior, Jesus Christ, for dying on the Cross so that I may have eternal life.

\section{Acknowledgements}

I would like to thank a number of people who, without their help, made this thesis possible. I would like to take this opportunity to thank not only the individuals who have contributed to my thesis, but also those who have assisted me throughout my specialty training.

Dr. Richard Jurevic, for being the chairman of my thesis committee and guiding me throughout this process. Without your help this would not have been possible, I thank you

Dr. Peter Ngan, for being a member of my thesis committee, for your countless hours of dedication to this program, and for your endless commitment to me, I thank you.

Dr. Chris Martin, for being a member of my thesis committee, for being a fulltime adviser, and for guiding me through my educational journey, I thank you.

Dr. Tom Shipley, for your contribution of CBCT scans of subjects utilized throughout this research project and for your continued dedication and drive to produce evidenced based studies, I thank you.

Dr. Erdogen Gunel, for your time and effort in preparing and interpreting the statistical analyses conducted throughout this project, I thank you.

Drs. Glenn Boyles, John Dempsey, Dan Foley, Mike Hazey, Tom Jarrett, Kerry Kirsch, Scott Little, Ned McFarland, Rajia Sebbahi, Tim Tremont, and Lew Wright, for your time and enthusiasm granted to this program. You are 
great examples and set a standard in which to aspire. I am thankful that I was given the opportunity to learn from you. Each of you have had a significant impact in preparing me as an orthodontist, I thank you.

Karen Pacilli, Sandy Cooke, and Leona Wolfe, for your support and special assistance offered in clinic. You are an asset and I am so grateful to have gotten the opportunity to work with you. I thank you.

Sherri Whitacre, Carol Rodeheaver, Carrie Trejo, and Brittany Winland, for your support and assistance. You all know better than some, I need it. I am grateful to have gotten the opportunity to work with you, I thank you.

Nicole DeShon and Deepa Vyas- my fellow classmates, for your support you have shown me through our time together. Good luck to each of you in your future endeavors and I thank you.

Ronnie, Holly, Jung Mee, Chad, Doyoung, and Alice - my former residents, for being leaders, role models, and teachers. Most importantly, however, were the friendships we developed throughout the course of this residency. The previous two years were quite an experience and you all made it one of the most memorable times of my life. I miss all of you and I thank you.

Nick, Travis, Jen, Martin, Tim, and Jason - my current residents, for being insightful, giving, and willing to listen when I needed it most. Like the previous residents listed above, we too have sparked friendships that I know will be everlasting. Good luck to each of you in your future endeavors and I thank you. 


\section{Table of Contents}

\begin{tabular}{lc} 
Abstract & ii \\
\hline Dedications & iii \\
\hline Acknowledgements & iii \\
\hline Table of Contents & $\mathbf{v}$ \\
\hline List of Figures & vii \\
\hline List of Tables & viii \\
\hline Chapter I - Introduction & $\mathbf{1}$ \\
\hline Statement of the Problem & 1 \\
\hline Significance of the Problem & 1 \\
\hline Purpose of the Study & 2 \\
\hline Null Hypothesis & 2 \\
\hline Definition of Terms & 3 \\
\hline Assumptions & 9 \\
\hline Limitations & 9 \\
\hline Deliminations & 9 \\
\hline Chapter II - Review of the Literature & 10 \\
\hline Mandible Growth and Development & 10 \\
\hline Anatomy of the TMJ & 10 \\
\hline Maxillary Transverse Deficiency & 12 \\
\hline Posterior Crossbite & 16 \\
\hline Types of Crossbites & 18 \\
\hline Detection of Joint Changes & 18 \\
\hline Changes IN TMJ with FUPXB & 20 \\
\hline CBCT & 25 \\
\hline Chapter III - Experimental Design and Methods & 27 \\
\hline Imaging Protocol & 27 \\
\hline Methodology & 28 \\
\hline Condyle and TMJ analysis & 31 \\
\hline Statistical Analysis & 33 \\
\hline Chapter IV - Results & 34 \\
\hline Study Demographics & 34 \\
\hline Transverse Measurements & 36 \\
\hline Molar Angle to the Functional Occlusal Plane & 37 \\
\hline Condyle Size and Orientation & 39 \\
\hline Condyle position within the Glenoid Fossa & 40 \\
\hline Chapter V - Discussion & 45 \\
\hline Imaging & 45 \\
\hline Study Demographics & 46 \\
\hline Transverse Analysis & 47 \\
\hline Molar Angle to the Functional Occlusal Plane & 49 \\
\hline Joint Space Analysis & 50 \\
\hline & 50 \\
\hline
\end{tabular}


Limitations

56

Chapter VI - Summary and Conclusions $\quad 58$

Chapter VII - Recommendations for Future Research $\quad 60$

References

Appendices

Appendix A - Dr. Shipley Authorization 


\section{List of Figures}

Figure 1: Image of a properly oriented CBCT image.

Figure 2: Image of the dental transverse measurements and the molar inclinations.

Figure 3: View of the imaging planes for joint space analysis. 


\section{List of Tables}

Table 1: Distribution of subject demographics for the entire sample. 35

Table 2: Distribution of the Control Group and Distribution of the Crossbite Group

Table 3: Vanarsdall's Transverse Differential Index

Table 4: Miner's Transverse Analysis

Table 5: Upper and lower right and left first molar axial inclination to the functional occlusal plane.

Table 6: Compare right and left molar inclination on the same patient 38

Table 7: Condylar Width and Condylar angle to the midsagittal plane 39

Table 8: Compare right and left condylar width and midsagittal angle on the same patient.

Table 9: Anterior, superior and posterior joint spaces for the medial, center, and later measurements for the right condyle of the control group and noncrossbite on the crossbite group.

Table 10: Anterior, superior and posterior joint spaces for the medial, center, and later measurements for the left condyle of the control group and crossbite condyle on the crossbite group.

Table 11: Compare the right side condyle joint spaces to the left condyle joint spaces in the control group.

Table 12: Compare the noncrossbite side condyle joint spaces to the crossbite condyle joint spaces.

Table 13: Reliability Coefficients of all joint space measurements. 


\section{Chapter I - Introduction}

\section{Statement of the Problem:}

The unilateral posterior crossbite with a functional shift is one of the most common early adolescent malocclusions. It is caused by a transversely deficient maxilla, relative to the mandible, and results when the mandible shifts to one side to so the teeth can maximally interdigitate. This shift is thought to cause the contralateral condyle to move anteriorly, inferiorly, and medially within the temporomandibular joint (TMJ). Much attention has been given recently to the affects of this functional shift on the condyles. An attempt to determine if pathological position of the condyles can cause condylar signs or symptoms similar to degenerative joint disease (DJD) or juvenile condylar resorption (JCR), or cause the position of the condyle is in an altered position within the TMJ. Only a few studies have evaluated condylar position within the TMJ using CBCT, with varying results. This study will attempt to determine if the presence of a unilateral posterior crossbite with a functional shift will result in a difference in condylar position within the joint.

\section{Significance of the Problem:}

Sparse documentation exists on cone beam computed tomography (CBCT) evaluation of the condyle position and surface changes. This information could be used to properly evaluate the effect of unilateral posterior crossbite correction on condylar position and surface changes. Without first establishing 
the effect of unilateral posterior crossbite on the condyles, the post-treatment result cannot be determined adequately. Much more information is needed to understand the effect of unilateral posterior crossbite on the condyles.

\section{Purpose of the Study:}

The aim of this study is to evaluate the maxillary and mandibular transverse discrepancies by the Vanarsdall and Miner approaches. We will evaluate condylar width and condylar angle to the midsagittal plane, positional differences between crossbite side and non crossbite side condyles, and condylar osseous changes, such as progressive condylar resorption (PCR), in the study and control groups. We hypothesize that osseous changes, between the right and left sides, will be present on significantly more patients with FUPXB than children without a crossbite or functional shift, and we also hypothesize that the effected side will be further from the glenoid fossa than the noncrossbite side.

\section{Null Hypothesis:}

1. There will be no difference in the maxillary and mandibular transverse dimensions by the Vanarsdall approach in the study compared to the control in untreated orthodontic patients.

2. There will be no difference the maxillary and mandibular transverse dimensions by the Miner approach in the study compared to the control. 
3. There will be no difference in the angle of the maxillary and mandibular first molars between the study and control groups, and between the crossbite and non crossbite sides of the study group.

4. There will be no difference in the width of right and left condyles in the study compared to the control.

5. There will be no difference in the condylar angle to the midsaggital plane between the control and the study groups, and between the crossbite and non crossbite sides of the study group.

6. There will be no difference in position of condyles in the TMJ, when comparing similar points, between the control and the study groups, and between the crossbite and non crossbite sides of the study group

7. There will be no difference in the signs of osseous changes of the control group to the study group.

\section{Definition of Terms}

- 2D - Two Dimensional (2-Dimensional)

- Refers to objects that are rendered visually on paper, film or on screen in two planes ( $\mathrm{X}$ and $\mathrm{Y}$; width and height). Two-dimensional structures or images are used to simulate 3D objects. In the computer, a 2D drawing program can be used to illustrate a 3D object; however, in order to interactively rotate an object in all axes, it must be created as a 3D drawing in a 3D drawing program.

- 3D - Three Dimensional (3-Dimensional) 
- Refers to objects that are rendered visually on paper, film or on screen in three planes ( $\mathrm{X}, \mathrm{Y}$ and $\mathrm{Z})$. 3D images are true representations of $3 \mathrm{D}$ objects.

- Centric Relation (CR)

- The maxillo-mandibular relationship in which the condyles articulate with the thinnest avascular portion of their respective discs with the complex in the anterior-superior position against the slopes of the articular eminences. This position is independent of tooth contact. This position is clinically discernible when the mandible is directed superiorly and anteriorly. It is restricted to a purely rotary movement about the transverse horizontal axis

- Cephalogram

○ Synonym for a cephalometric radiograph.

- Cephalometric analysis

- An analysis made on a radiograph of the head (cephalometric radiograph) comprised of referents and landmarks used to describe relationships of skeletal and dental components, usually compared to a norm.

- Cephalometric radiograph

- A radiograph of the head made with reproducible relationships between the $\mathrm{x}$-ray source, the subject, and the film.

- Computed tomography (CT) 
- A series of radiographs (flat, two-dimensional grayscale images) that are analyzed and rendered via computer to produce a threedimensional volumetric or surface mapped image. Also referred to as Medial CT or MCT.

- Cone Beam Computed Tomography (CBCT)

- A computed tomography scan utilizing an x-ray beam in the shape of a cone to provide images of bony structures. Data is captured by a flat receiver that detects pulses of cone shaped beam radiation. The result is a stack of two-dimensional grayscale images of the anatomy which can be rendered into volumetric data to visualize anatomical structures in three dimensions. Also known as Cone Beam Volumetric Tomography (CBCT)

- Degenerative joint disease (DJD)

- Mechanical abnormality involving degradation of joints, including articular cartilage and subchondral bone. It associated with loss of cartilage and bone exposure and damage. It has many causes including hereditary, developmental, metabolic, and mechanical deficits.

- Digital Imaging and Communications in Medicine (DICOM)

- DICOM is a standard for handling, storing, printing, and transmitting medical images.

- Frankfort Horizontal Plane 
- A horizontal plane represented in profile by a line between the lowest point on the margin of the orbit and the highest point on the margin of the auditory meatus.

- Frankfort - Mandibular Plane angle (FH/MP)

- The angle formed at the intersection of the Frankfort horizontal plane with the Mandibular Plane. This angle is often used to define the vertical dimension in human facial forms. This angle defines whether a patient is hyperdivergent, hypodivergent, or normodivergent.

- Image intensifier

- Allows real time image feed to an analog or digital receiver for compilation or viewing of live radiographic images.

- Landmark

- A fixed, reproducible (anatomical) point of reference on a radiograph.

- Mandibular Plane

- A plane constructed from the most anterior inferior portion of the mandible, termed mention, and the most inferior posterior boarder of the mandible termed gonion.

- Maximum Intercuspation (MI), Centric Occlusion (CO), and Intercuspal Position (ICP)

- The occlusal position of the mandible in which the cusps of the teeth of both arches fully interpose themselves with the cusps of 
the teeth of the opposing arch. This is also referred as centric occlusion and intercuspal position.

- Progressive Condylar Resorption (PCR)

- A localized noninflammatory degenerative disorder of the TMJ's that is characterized by lysis and repair of the articular fibrocartilage and underlying subchondral bone, occurring most commonly during puberty in female individuals.

- Referent

- A variable, reproducible (anatomical) point related to a landmark on a radiograph.

- Resolution

- The smallest distance between two points at which the viewer can still distinguish the two points as separate entities. Higher resolutions provide finer detail.

- Sievert (Sv)

- Standard international (SI) unit of radiation dose equivalent. This unit of measure reflects the biological effects of radiation (as opposed to the physical aspects which are characterized by absorbed dose measured in Grays).

- Temporomandibular joint (TMJ)

- It is a bilateral synovial articulation between the mandibular condyle and the temporal bone. It is a ginglymoarthrodial joint that provides the mobility of the mandible during masticatory, speech, and other 
oral processes. The unique feature is a dense fibrocartilage articular disc between the condyle and temporal bone.

- Tomogram

- A radiograph representing a "slice" or sectioned focal area by moving an $\mathrm{x}$-ray source and the film in opposite directions during exposure. Structures in the focal plane appear sharp, while structures in front of and behind the plane are blurred.

- Unilateral Posterior Crossbite with a Functional Shift

- This malocclusion present with a unilateral posterior crossbite with a fuctional shift from centric relation to maximum intercuspation that can be determined clinically. It is associated with a symmetrically transverse deficient maxilla and at least one posterior tooth in crossbite.

- Volumetric

- Visual representation of an image in three dimensional space.

- Voxel

- The smallest element in building a three-dimensional image. It is similar to a "pixel" in a flat two-dimensional image display. Voxel size is important in defining the resolution of a volumetric image (smaller voxel size $=$ higher resolution). The voxel size of a CBCT image can be as small as 0.16 cubic millimeters while the voxel size of a traditional CT image is 0.32 cubic millimeters. 


\section{Assumptions:}

It is assumed that the CBCT scans are of sufficient quality with no patient movement contributing to the introduction of radiographic artifacts, that the operator in this study has a working knowledge of computer technology, and that the landmarks can be accurately identified using Cone-Beam Computed Tomography technology. It also assumed that the CBCT scans on subjects were taken in centric occlusion or maximum intecuspation, and that the CBCT scans on subjects were taken prior to initiation of any type of orthodontic or orthopedic treatment.

\section{Limitations:}

There will be gender, ethnicity, and medical history differences among the subjects. Scans may contain artifacts depending on patient movement and machine calibration. Measurements are limited to the researcher's ability to accurately manipulate the $\mathrm{CBCT}$ image. The study is limited to the private practice subject database of Thomas Shipley, D.M.D., M.S. of Peoria, AZ.

\section{Deliminations:}

One researcher will orient all CBCT images according to the standard X-, Y-, and Z- axes. One researcher will make all measurements using the CBCT scan. The study will be limited to 3D Cone-Beam Computed Tomography scans on subject's pre - orthodontic treatment. Only one CBCT unit from Dr. Shipley's office was used to take the images, i-CAT 17-19 Next Generation. 


\section{Chapter II - Review of Literature}

\section{Mandible Growth and Development:}

Enlow has clearly defined the changes that occur during growth and development of the mandibllar body and condyle (1). The body intramembranously develops by surface apposition, and the condyle develops by endochondral proliferation. The anterior borders of the mandible body above the bony chin, the anterior ramus, and the posterior inferior border of the mandible are areas of resorption, while the posterior border of the ramus, the anterior inferior border of the mandible, and the chin are areas of deposition. From Bjork's implant study, it is understood that the condyle is an active growth site, and that there is some intrinsic capability of the condyle to grow posteriorly and superiorly (2). Conversely, the condyle/ramus complex has an adaptive response to the nature of the surrounding soft tissues and complexes acting upon. Gu and McNamara, in 2007, studied mandibular growth over superimposition of metallic implants over the evaluation of cervical vertebral maturation scales from CS1 to CS6. They found typical mandibular changes including forward upward orientation of the ramus due to, in part, condylar vertical growth (3).

\section{Anatomy of the Temporomandibular Joint:}

The temporomandibular joint (TMJ) is a compound joint and one of the most complex joints in the body. It is ginglymoarthrodial joint that both hinges 
and translates. The TMJ is formed by the mandibular condyle articulating with the glenoid fossa of the temporal bone separated by the articular disc. The condyle is a convex articular surface consisting of a more prominent medial pole and a less prominent lateral pole. In the adult patient, the mediolateral length of the condyle is 15 to $20 \mathrm{~mm}$ and the anteroposterior width is $8-10 \mathrm{~mm}$. The glenoid fossa is the concave articulating surface for the condyle. Anterior to the glenoid fossa is the articular eminence that has a significantly variable degree of convexity. The articular disc is fit between the condyle and glenoid fossa, and serves as the nonossified bone that allows movements of the joint. The disc and articulating surfaces of the condyle and articular fossa are comprised of dense fibrous connective tissue. From a sagittal view, the disc is biconcave in shape with a thin intermediate zone surrounded by a thick anterior band and slightly thicker posterior band. From an anterior view, the precise shape is variable depending on morphology, but is generally thicker medially than laterally. The disc is slightly flexible and can mildly adapt to the articular surfaces of the condyle and articular eminence during function. Posteriorly, the disc is attached to highly vascularized and innervated tissue called the retrodiscal tissue. Superior to the retrodiscal tissue, is the superior retrodiscal lamina highly comprised of elastic fibers. The inferior retrodiscal lamina is comprised mainly of collagenous fibers. Anterior attachments of the disc are to the capsular ligament, which surrounds the majority of the joint, tendons of the lateral pterygoid muscle, superiorly to the articular surface of the temporal bone, and inferiorly to the anterior border of the articular surface of the condyle. The disc attaches to the 
capsular ligament medially and laterally as well with the collateral ligaments. The capsular ligament attaches superiorly to the temporal bone and the articular eminence and inferiorly to the neck of the condyle (4).

The TMJ has two compartments, formed by the disc, for different purposes during function and mastication. The superior compartment allows for translation, and the inferior compartment, also known as the condyle-disc complex, serve for hinge movement of the joints. During rest there is a base interarticular pressure from a static tonus from the muscles of mastication that allow the articular surfaces of the joint to be maintained, and during function the interarticular pressure of the joint increases (4). As individuals grow and develop, the growth sites of the mandible are the posterior ramus and the condylar and coroniod processes. As described, the temporomandibular joint is very complex in it's nature, and has an incredible adaptive ability to provide function in the developmet of a diverse array of occlusions and malocclusions, such as a posterior crossbite.

\section{Maxillary Transverse Deficiency:}

There are my different types of crossbites, and they can be attributed to either dental or skeletal maxillary transverse discrepancies. Howe, in 1983, found that the typical non crowded width of the maxilla was $36-39 \mathrm{~mm}$, measured at the most lingual aspect of the maxillary first molars, and those with arch widths less than $31 \mathrm{~mm}$ were often crowded and were in need of expansion, either orthopedic or surgically assisted (5). In 1981, the Angle Orthodontist editorial 
"Fifty Years of Cephalometric Radiography," stated "We treat in three dimensions... we can no more close our eyes to the information in the frontal view than we could afford to ignore the lateral view up to now" (6). Ricketts published an article, in the same journal, the Rocky Mountain Analysis, which described specific radiographic landmarks and measurements to assess the transverse dimension between the maxilla and mandible (7). The landmarks where maxillary and mandibular transverse dimensions are measured are jugale right (JR), jugale left (JL), antegonion right (AG), antegonion left (GA), zygomatic right (ZR), and zygomatic left (ZL). Actual effective maxillary width is determined by the linear measurement from $\mathrm{JR}$ to $\mathrm{JL}$, and jugal points occur at the intersection of the outline of maxillary tuberosity and the zygomatic buttress. Actual effective mandibular width can be determined by the linear measurement from $A G$ and $G A$, and the antegonial points occur at the lateral inferior margin of the antegonial protuberance, just below the antegonial trihedral area. The maxillomandibular transverse differential index is defined as the expected maxillomandibular transverse differential minus the actual maxillomandibular transverse differential (8). The expected maxillomandibular transverse differential norms provided here are based on Caucasian individuals. This maxillomandibular differential index was described by Vanarsdall and is named the Vanarsdall Transverse Differential Index. 


\section{Maxillomandibular Transverse Differential Index}

\begin{tabular}{|c|c|c|c|c|c|}
\hline & & $9 \mathrm{Yr}$ Old & $\begin{array}{c}\text { Change/Yr to } \\
\text { age } 16\end{array}$ & $\begin{array}{c}\text { Normal } \\
\text { (Expected) } \\
\end{array}$ & $\begin{array}{l}\text { Patient } \\
\text { (Actual) }\end{array}$ \\
\hline $\begin{array}{l}\text { Effective Mandibular } \\
\text { Width }\end{array}$ & (GA to $A G)$ & $76 \pm 3 \mathrm{~mm}$ & $+1.4 \mathrm{~mm}$ & & \\
\hline $\begin{array}{l}\text { Effective Maxillary } \\
\text { Width }\end{array}$ & (JR to JL) & $62 \pm 3 \mathrm{~mm}$ & $+0.6 \mathrm{~mm}$ & & \\
\hline
\end{tabular}

\begin{tabular}{|c|c|c|c|}
\hline \multicolumn{5}{|c|}{ Normal Values } \\
\hline$\underline{\text { Age }}$ & $\underline{\text { Maxillary }}$ & $\underline{\text { Mandibular }}$ & $\underline{\text { Difference }}$ \\
\hline 9 & 62.0 & 76.0 & 14.0 \\
\hline 10 & 62.6 & 77.4 & 14.8 \\
\hline 11 & 63.2 & 78.8 & 15.6 \\
\hline 12 & 63.8 & 80.2 & 16.4 \\
\hline 13 & 64.4 & 81.6 & 17.2 \\
\hline 14 & 65.0 & 83.0 & 18.0 \\
\hline 15 & 65.6 & 84.4 & 18.8 \\
\hline 16 & 66.2 & 85.8 & 19.6 \\
\hline (Adult) & & & \\
\hline
\end{tabular}

Expected Maxillomandibular Diff. $=$ Expected Mand. Width - Expected Max. Width $=$ $\mathrm{mm}$ Actual Maxillomandibular Diff. $=$ Actual Mand. Width - Actual Max. Width $=$ $\mathrm{mm}$ Expected - Actual Maxillomandibular Differential = $\mathbf{m m}$.

The tables provided are based out of Vanarsdall's 1999 publication, "Transverse Dimension and Long-Term Stability" (8).

There are many factors that cause concerns when using posterioanterior cephalometric analysis. Many structures are superimposed, and landmark 
identification errors occur more frequently than desired for accuracy and clinical implementation $(9,10)$. Also, any deviation from normal in the orientation of the head within the cephalostat can affect the relationship of landmarks $(11,12)$. This makes it harder to assess symmetry and measure horizontal distances. Also, landmarks located farther from the posterioanterior porionic axis have greater variations and are affected by head rotation to a greater extent, making this method of evaluation of the transverse dimension more difficult $(12,13)$. CBCT scans have the potential to reduce some of these common errors attributed to 2-D cephalometrics and can also accurately analyze asymmetry, condylar pathology, airway patency, and skeletal discrepancies $(14,15)$. It has also been proven that $\mathrm{CBCT}$ measurements are more precise compared to traditional 2-D measurements of anatomic measurements $(16,17)$.

The JR-JL:AG-GA differential has been the standard maxillomandibular method of comparison until recently. Miner, et al. in 2012, published an article describing a new method of evaluating the transverse dimension (18). They measured the axial angle of the maxillary and mandibular first molars compared to the functional occlusal plane, the maxillary and mandibular midalveolar process widths, and then calculated the difference between the maxillary and mandibular midalveolar widths. Their normal data was taken from 1 standard deviation from the noncrossbite group molar inclination. They found that patients with or without crossbites can have significant maxillomandibular transverse discrepancies that might warrant treatment. 


\section{Posterior Crossbite:}

Posterior crossbite (PXB) is defined as an abnormal buccal-lingual relationship of opposing maxillary and mandibular molars, premolars, or both in intercuspal position (ICP). This occurs when the maxillary posterior teeth or jaw is narrower than the mandibular posterior teeth or jaw, and can occur either bilaterally or unilaterally. Unilateral posterior crossbite (UPXB) is a relatively common malocclusion found in children in the early and mixed dentitions, and can occur with or without a functional shift (FUPXB) to the crossbite side from centric relation (CR) to ICP. Posterior crossbite can develop or self correct at any point during the eruption of the primary dentition to the eruption of the permanent dentition (19-22). The reported incidence of posterior crossbite ranges from $7 \%$ to $23 \%$ in primary, mixed and permanent dentitions $(20,22-25)$. Frequency of UPXB occurs $5.9 \%$ to $9.4 \%$ of the total population, while FUPXB is the most common form of posterior crossbite occurring from $80 \%$ to $97 \%$ of all posterior crossbite cases $(20,26-29)$. FUPXB occurs in the primary dentition is $8.4 \%$ and $7.2 \%$ in the mixed dentition (24). The frequency of self-correction of posterior crossbites ranges from $0 \%$ to $9 \%$ while natural development of crossbites not previously present is $7 \%(20,24)$.

The etiology of posterior crossbites is unclear, but has been related to many factors or a combination of many factors that included dental, skeletal, soft tissue, respiratory, functional neuromuscular, or habitual abnormalities (30-34). Dental abnormalities relating to PXB include can include one or multiple teeth. 
Simple crossbites include one tooth that is deflected out of the arch line by deficient arch length, abnormal eruption pattern, or over retention of a deciduous tooth (24). It is possible for a normal maxillary width to be present with a lingual version of the maxillary molars causing dental crossbite involving multiple teeth. It is reported there are three maxillary/mandibular relationships present in a skeletal posterior crossbite: narrow maxilla, normal mandible; normal maxilla, wide mandible; and narrow maxilla, wide mandible (35). A reduced maxillary intermolar width is often attributed to a skeletally narrow maxilla causing a posterior crossbite, and narrow maxillas can have genetic and environmental etiologies. Skeletal factors influencing posterior crossbites include smaller maxillary to mandibular intermolar dental width ratio and greater lower face height (36). Upper airway obstruction, infantile intubation, and non-nutritive sucking habits are environmental factors associated with posterior crossbites caused by a narrow maxillary width. Upper airway obstruction from hypertrophied adenoids or tonsils and allergic rhinitis can result in mouth breathing and have a higher correlation with the development of posterior crossbites $(33,37,38)$. Neonates who have been intubated also have significantly higher prevalence of posterior crossbites (39). Many studies have showed that children of various ages from two to six years old with finger and pacifier sucking habits have an increased incidence of posterior crossbite (31, 40-42). It is important to note that all these factors and likely etiologies for posterior dental crossbites are not absolutely suggestive of a direct cause and effect relationship with posterior crossbites. 


\section{Types of Crossbites:}

Functional unilateral posterior crossbites present with a unilateral crossbite with a fuctional shift from CR to ICP that can be determined clinically. It is associated with at least one posterior in crossbite and the midlines are usually not aligned. In maxillary skeletally narrow crossbites, the severity of maxillary transverse deficiency is less in FUPXB than in bilateral crossbites. As the mandible bodily shifts from CR into ICP, the skeletal mandibular midline, and frequently dental midline, are deflected to the crossbite side. The patient appears asymmetric with FUPXB, but the mandible is not asymmetric, only positioned asymmetrically. This is to be differentiated from true skeletal crossbites where the etiology is an asymmetric mandible without a CR-ICP shift. The maxillary arch is also usually symmetric while the maxilla is transversely constricted in a FUPXB. The constriction is often accompanied with excess maxillary crowding due to the decreased arch length as compared to the mandibular arch. Because of the rotational closure of the mandible in the FUPXB, the crossbite side often is a partial to full step Class II molar relationship while the non-crossbite side shows a Class I molar relationship (43).

\section{Detection of Joint Changes:}

It has been established that clinical exams are not reliable for accurate diagnosis of TMD in patients with signs and symptoms of internal joint derangements (44). It has also been published that some form of radiographic 
exam is essential in the diagnosis of TMD, and cone beam computed tomography is superior to conventional radiography due to the lack of superimposition of structures found conventionally (45). This diagnostic imaging of both hard and soft tissues has significantly increased the understanding of the TMJ and associated disorders. Through the 1970's and 1980's, arthrography was the leading soft tissue exam for TMJ. During the 1980's computed tomography was used to evaluate the TMJ, but is mainly useful for osseous abnormalities due to inferior soft tissue resolution. During the 1980's and 1990's magnetic resonance (MR) imaging has become the ideal modality for soft tissue TMJ diagnosis (46). TMJ bony changes are currently evaluated by panoramic radiography, linear or complex motion conventional tomography (CT), and computed tomography with helical or multi-slice CT or CBCT. It is important to note that radiography can only detect condyle-fossa relationship and the severity of osseous abnormalities. Osseous changes from degenerative arthritis that can be determined within the TMJ are loss of articular cortication, erosions, sclerosis, flattening of the articular surfaces, and osteophyte formation $(47,48)$.

In 2004, Tsiklakis, et al. outlined a reconstruction technique for examination of the TMJ using $\mathrm{CBCT}$, and determined that a comprehensive radiographic evaluation of the bony components of the TMJ could be completed. It was concluded that CBCT should be the imaging technique of choice when evaluating bony changes of the TMJ (49). A systematic review by Hussain, et al. in 2008 reviewed articles pertaining to the diagnostic capability of different imaging modalities to asses TMJ erosions and osteophytes. As quoted by 
Hussain ,et al., "axially corrected sagittal tomography (ACST) is currently the imaging modality of choice for diagnosing erosions and osteophytes in the TMJ".

CT does not add additional information that cannot be found from the axially corrected sagittal tomography. It was also determined that CBCT has a similar or higher diagnostic capability than helical CT (HCT), and was a viable choice for detecting TMJ erosions and osteophystes. (50). Honey, et al. found CBCT images to be more reliable and have greater accuracy in the detection of condylar cortical erosion than corrected angle linear tomography and TMJ panoramic projections (51). Intraobserver reliability of $\mathrm{CBCT}$ images were substantially greater than plane projection linear tomography. A more recent study in 2012 by Zain-Alabdeen and Alsadhan, determined that CBCT accuracy for detecting surface osseous changes like erosions and osteophytes was comparable to multidetector CT (MDCT) and should be encouraged because CBCT has less radiation exposure. High accuracy with intraovserver reliabilities was also found (52).

\section{Changes in the TMJ with Unilateral Posterior Crossbite with a Functional}

\section{Shift:}

In 2009, Ikeda and Kawamura published a study where limited CBCT was used to find the optimal position of the mandibular condyle within the glenoid fossa. All of the subjects joints were completely symptom free, and the position of the articular disc was verified by MRI analysis. The joint spaces found were 
statistically significant. The joint spaces were AS of $1.3 \mathrm{~mm}$, SS of $2.5 \mathrm{~mm}$, and PS of $2.1 \mathrm{~mm}(53)$.

Positional differences of the condyles in FUPXB have been reported for the crossbite and non-crossbite side. Tomograms reveal that in ICP, the crossbite side condyle is forced upward and backward in the glenoid fossa while the condyle is distracted forward in the non-crossbite side (43). If the mandible itself is asymmetric and is causing the UPXB's, there is no difference in the condylar position in the joint spaces, which is different if there is a symmetric mandible with functional shift. In animals, it has been shown that altering mandibular position with either bite planes or occlusal grinding, results in alterations in muscular and skeletal growth patterns with changes occurring at the ramus and condyle (54-56). Fuentes, et al. describes how lateral functional shift of the mandible can affect the condylar cartilage thickness and proliferation, and the gene expression in condylar cartilage. Mandibular condylar cartilage thickness was significantly greater at the majority of timepoints on the protruded side, while the nonprotruded side trends were generally opposite (27). Condylar cartilage thickness and proliferative activity might accompany those with a lateral functional shift. Additionally they examined the relationship of gene expression insulin-like growth factor-1 (IGF-1) and fibroblast growth factor-2 (FGF2) and four of their receptors and found that gene expression was significantly different between the protruded and nonprotruded side, and the mRNA expression was opposite most of the time within the protruded and nonprotruded condyles (57). Liu, et al. found that rats exposed to a $2 \mathrm{~mm}$ left shift had developed asymmetric 
mandibles. The length of the condylar head was greater on the ipsilateral side, and the mandible on the ipsilateral side grew in a more anterior superior direction (58).

Growth changes that could occur by alterations in mandibular position, can benefit, damage, or have no effect on the structures of the TMJ. Any type of damage to the TMJ is considered TMJ disease (TMD). It was shown that if the crossbite is not corrected the mandible may grow and develop asymmetrically due to the lateral displacement and asymmetric muscle function (59).

In 1980, Myers, et al. used pre- and post-treatment transcranial radiographs and identified significant differences in the vertical (superior) and horizontal (anterior) measurements on either the crossbite or noncrossbite side pretreatment, and there were no significant differences post treatment. They also found that the superior joint space and anterior joint space was increased on the noncrossbite side. They concluded there is potential for adaptive growth changes to occur if the mandibular shifting occurred resulting from malocclusion (60). A more elaborate pilot study using transcranial radiographs was performed by Nerder, et al. in 1999 (61). The position of the condyles prior to treatment, during the use of a splint, and post retention was investigated. Erosions, sclerosing, and flattening was not found, and the position of the crossbite and noncrossbite side condyles were similar. However, upon placing a flat plane splint, the crossbite side was displaced $1.3 \mathrm{~mm}$ forward. Upon completion of treatment, there was not discernment between the crossbite and noncrossbite side condyles (61). The study concluded that transcranial radiographs give 
"rough indication of the condylar position," and the original positions of the condyles likely have been compensated by surface modeling within the TMJ. Unfortunately, the use of transcranial radiographs introduces potential error when measuring condylar position, because the scans have compromised image quality and projection effects. Mongini described how transcranial radiographs do not allow a detailed description of the condyle fossa relatioship (62). Hesse, et al. performed a tomographic analysis of the condylar position in patients with a FUPXB in 1997 on patients before and after expansion treatment (43). The noncrossbite condyle moved posteriorly and superiorly from before to after expansion treatment, and the superior joint space was the greatest on the noncrossbite side before treatment. Relative condylar position was more anterior on the noncrossbite side before treatment, but both sides were similar after treatment. Pinto, et al., in 2001, analyzed mandibular morphology using submentovertex radiographs (SMV), and also analyzed joint space symmetry with zonograms. Zonograms are 4 turn spiral complex motion tomography, and were taken at $15^{\circ}, 20^{\circ}, 25^{\circ}$, and $30^{\circ}$ from the midsagittal plane with thickness layers of $16 \mathrm{~mm}$. They observed the ramus, both the condyle and the coronoid, was significantly longer on the noncrossbite side, the posterior and superior joint spaces were larger on the noncrossbite side, and the mandible was without any significant morphological or positional asymmetries after treatment (63). In 2007, Kecik, et al. evaluated mandibular condylar position and morphological asymmetry using lateral, posteroanterior, and SMV cephalograms, transcranial temporomandibular joint radiographs, joint vibration analysis and 
electromyographic recordings. Before expansion treatment, mandibular asymmetry was present and the crossbite side was significantly smaller than the noncrossbite side, while the control groups had no statistical asymmetry present. Pretreatment, the posterior and superior joint spaces were significantly smaller on the crossbite side while the anterior joint space was greater on the crossbite side. After treatment, there were no differences between crossbite and non crossbite joint spaces (64).

Pellizoni, et al. used MRI to evaluate the position and configuration of the articular disc in those with and without a FUPXB, and all of their subjects had asymptomatic joints. No significant differences in disk position or morphology were found, but one joint in the control and one joint in the shift group had a folded disc (65).

In 2012, Leonardi, et al. performed a low dose CT study analyzing the crossbite and noncrossbite side condyles pretreatment and post treatment. No differences in position of the condyles pre-treatment were found, but significant increases in superior joint space on the non-crossbite side, and relative increases in anterior and posterior joint spaces on the noncrossbite sides occurred post treatment. Additionally, the posterior joint space increased only on the crossbite side post treatment (66). 


\section{Cone Beam Computed Tomography:}

Cone beam computed tomography utilizes a flat panel detector instead of an image intensifier (67). CBCT scanners have been available for craniofacial imaging since 1999 in Europe and since 2001 in the United States. The scanner utilizes a cone shaped $\mathrm{x}$-ray beam that pulses on and off as the scan is executed. The pulsing action reduces radiation exposure to the patient and shortens scan time. The cone beam scan produces raw data that requires the use of computer software in order to reconstruct volumetric data. This is in contrast to a conventional CT scanner that provides a set of consecutive slices of the imaged area (68).

The increase acceptance of CBCT in clinical orthodontics has influenced researchers to study the accuracy of CBCT. In 2007 , it was found that lateral cephalometric images rendered from CBCT data was more accurate than traditional lateral cephalometric headfilms (69). It is also found that many linear measurements between cephalometric landmarks on 3D volumetric surface renderings obtained using Dolphin 3D software generated from $\mathrm{CBCT}$ datasets may be statistically significantly different from anatomic dimensions, most can be considered to be sufficiently clinically accurate for craniofacial analyses (70).

With recent medical awareness of the general public, concern rises in the area of radiation safety with regards to radiographic imaging. The amount of radiation one receives from an $\mathrm{x}$-ray source depends on the field of view, the current multiplied by the scan time (mA), and the voltage (kVp) chosen. In 2004 radiation dose between a low-dose dental CT protocol, a standard CT protocol, 
and CBCT were compared (71). Standard dental CT protocols has an effective dose of approximately $3.4 \mathrm{mSv}$ and a low-dose protocol can be up to nine times less radiation (approximately $0.37 \mathrm{mSv}$ ). CBCT effective dose is approximately 0.11 to $0.5 \mathrm{mSv}$. However, some low-dose dental CT protocols might be superior to CBCT because the conventional CT can be used to evaluate soft tissue instead of high contrast, bony structures (72). A review article in 2006 summarized that the radiation dose from CBCT scanners have been reported to be 15 times lower than those of conventional CT scanners (a range from 0.04 to $0.05 \mathrm{mSv}$ ) which is a reduction of up to $98 \%$ compared with conventional dental CT scans ( 1.3 to $3.3 \mathrm{mSv}$ for imaging the mandible and 1.0 to $1.4 \mathrm{mSv}$ for imaging the maxilla) (73). Ultimately, the $\mathrm{CBCT}$ image volume requires much less radiation than that of a conventional dental CT scan but more radiation than that of a typical panoramic or cephalometric radiograph. The low radiation requirements are attributed to the pulse behavior of the x-ray beam in acquiring a cone beam image (72).

Being previously stated, many factors exist as a potential source for TMJ problems. Most chronic TMJ problems are associated with the aging process and arthritis and do not have one specific etiology. Functional shifts, associated with unilateral crossbite, abnormally load the TMJ and can cause joint and condylar abnormalities. 


\section{Chapter III - Experimental Design and Methods}

\section{Imaging Protocol}

This study was done in collaboration with Thomas Shipley, D.M.D., M.S. of Peoria, AZ. All the images were provided by and used with permission by Dr. Shipley. The images were donated for this study with the intent for use in research. All the patients were imaged in ICAT using the same settings, 14.7 acquisition time with a mAs of 20.27 and a $\mathrm{kVp}$ of 120 with a field of view of $17 \mathrm{~mm} \times 23 \mathrm{~mm}$ and voxel size of $0.3 \mathrm{~mm} \times 0.3 \mathrm{~mm}$. It was assumed that the CBCT scans on subjects were taken in centric occlusion and that the CBCT scans on subjects were taken prior to initiation of any type of orthodontic or orthopedic treatment. The subjects were selected randomly by starting with the most recent image and working backwards from the time of image collection. The entire database of Dr. Shipley was reviewed, about 1500 subjects. The DICOM files provided contained the age information of the subjects. The clinical examination findings were also provided to include the presence or absence of a FUPXB. The selection criteria for the DICOM file subjects were limited. The main criteria included patients seeking orthodontic treatment and a good quality

DICOM file image. The experimental group will also have a transverse maxillary deficiency with posterior crossbite (involving greater than one tooth) on one side only with the teeth at maximum intercuspal position as indicated by the clinical exam. 
Files will be excluded based on: no motion artifacts or other artifacts can be present, no developmental or acquired craniofacial deformity with or without mandibular/condylar involvement, no systemic disease, no history of orthodontic treatment, the control or experimental groups cannot have an anterior crossbite, no signs or symptoms of TMD according the the AAO medical history/exam, no missing teeth, excluding third molars, no carious lesions, extensive restorations, or pathologic periodontal status.

The control group was limited to the first 31 subjects meeting the inclusion and exclusion criteria. The study/crossbite group totaled 29 subjects which was inclusive of all the subjects meeting the inclusion and exclusion criteria within Dr. Shipley's database. The CBCT radiographs used in this study were deidentified and the experimental design was reviewed and considered Exempt by the Institutional Review Board at West Virginia University

\section{Methodology:}

The sixty DICOM files were analyzed using Anatomage, Inc. of California, InVivoDental 4.1 imaging software licensed to West Virginia School of Dentistry Department of Orthodontics. We assume that measurements are limited to the researchers' ability to accurately manipulate the CBCT image. The examiner was allowed to manipulate image brightness, contrast, and magnification, and use the secondary reconstruction tools in the software program.

Each file will be oriented according to criteria set forth by Cho: the sagittal plane will be derived from a best fit of nasion, crista galli, sella, and, basion, the 
axial plane will be parallel to Frankfort Horizontal, and the axial pane will be parallel to the frontozygomatic points (FZ) (74).

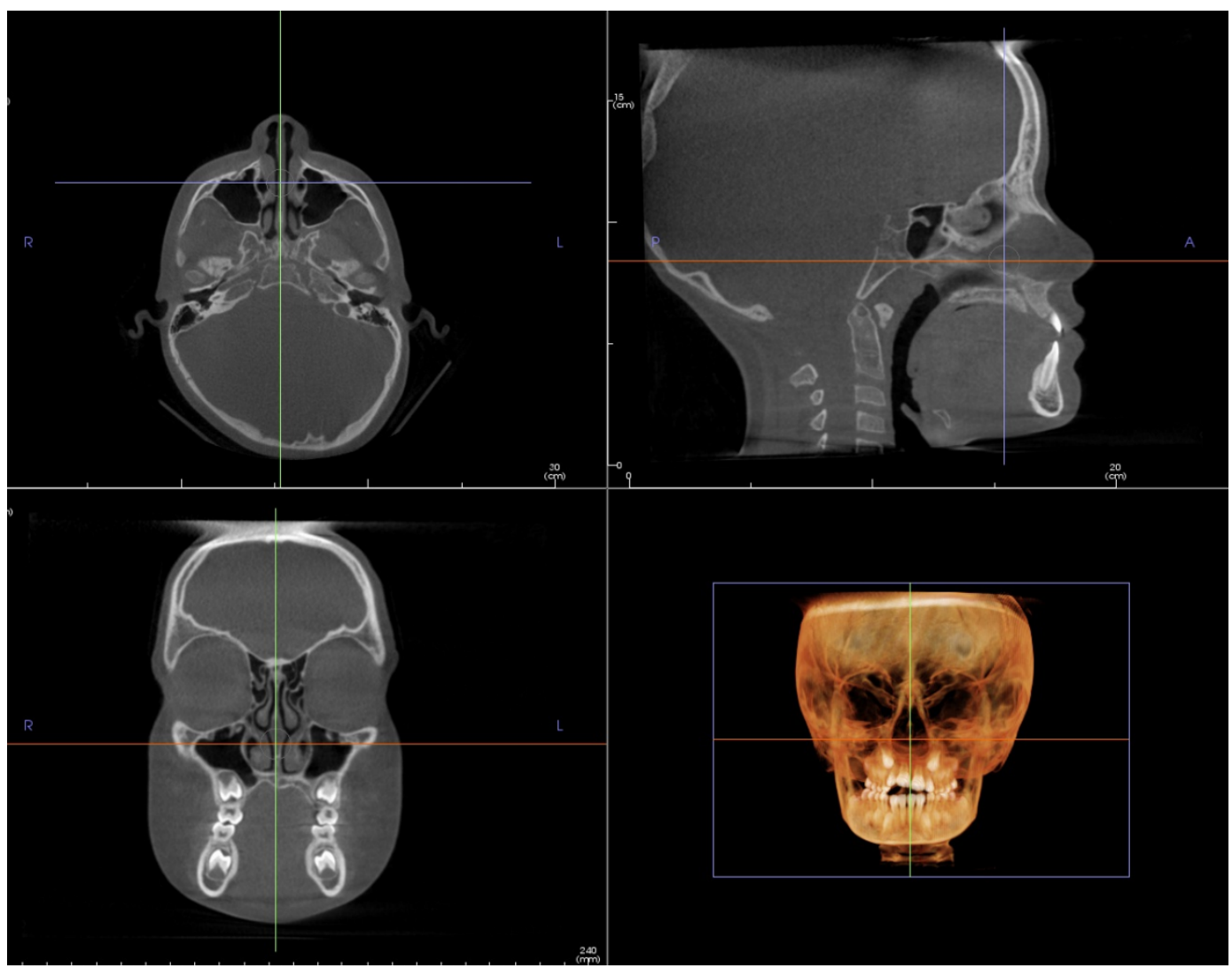

Figure 1: Image of a properly oriented CBCT image.

A lateral and posterior anterior cephalogram will be formed from the CBCT images and the following measurements will be measured in Dolphin Imaging, of California,10.5 Premium Software that was licensed to West Virginia University School of Dentistry Department of Orthodontics. From the lateral cephalogram SNA, SNB, ANB, SN-MP, Upper I to SN, and IMPA will be measured. From the posteroanterior cephalogram AG-GA and JR-JL will be measured and the Maxillomandibular Transverse Differential Index(8) will be calculated: 


\begin{tabular}{|c|c|c|c|c|c|}
\hline & & $9 \mathrm{Yr}$ Old & $\begin{array}{c}\text { Change/Yr to } \\
\text { age } 16\end{array}$ & $\begin{array}{c}\text { Normal } \\
\text { (Expected) }\end{array}$ & $\begin{array}{l}\text { Patient } \\
\text { (Actual) }\end{array}$ \\
\hline $\begin{array}{l}\text { Effective Mandibular } \\
\text { Width }\end{array}$ & (GA to $A G$ ) & $76 \pm 3 \mathrm{~mm}$ & $+1.4 \mathrm{~mm}$ & & \\
\hline $\begin{array}{l}\text { Effective Maxillary } \\
\text { Width }\end{array}$ & (JR to JL) & $62 \pm 3 \mathrm{~mm}$ & $+0.6 \mathrm{~mm}$ & & \\
\hline
\end{tabular}

\begin{tabular}{|c|c|c|c|}
\hline \multicolumn{5}{|c|}{ Normal Values } \\
\hline$\underline{\text { Age }}$ & $\underline{\text { Maxillary }}$ & $\underline{\text { Mandibular }}$ & $\underline{\text { Difference }}$ \\
\hline 9 & 62.0 & 76.0 & 14.0 \\
\hline 10 & 62.6 & 77.4 & 14.8 \\
\hline 11 & 63.2 & 78.8 & 15.6 \\
\hline 12 & 63.8 & 80.2 & 16.4 \\
\hline 13 & 64.4 & 81.6 & 17.2 \\
\hline 14 & 65.0 & 83.0 & 18.0 \\
\hline 15 & 65.6 & 84.4 & 18.8 \\
\hline 16 & 66.2 & 85.8 & 19.6 \\
$($ Adult $)$ & & & \\
\hline
\end{tabular}

Expected Maxillomandibular Diff. $=$ Expected Mand. Width - Expected Max. Width $=$ $\mathrm{mm}$

Actual Maxillomandibular Diff. $=$ Actual Mand. Width - Actual Max. Width $=$ $\mathrm{mm}$ Expected - Actual Maxillomandibular Differential = $\mathbf{m m}$.

Within each CBCT image the maxillomandibular difference according to Miner(18) will be completed. The axial angle of the maxillary and mandibular first 
molars compared to the functional occlusal plane and the maxillary and mandibular midalveolar process widths will be measured. The calculated the difference between the maxillary and mandibular midalveolar widths will be determined from the measurements.

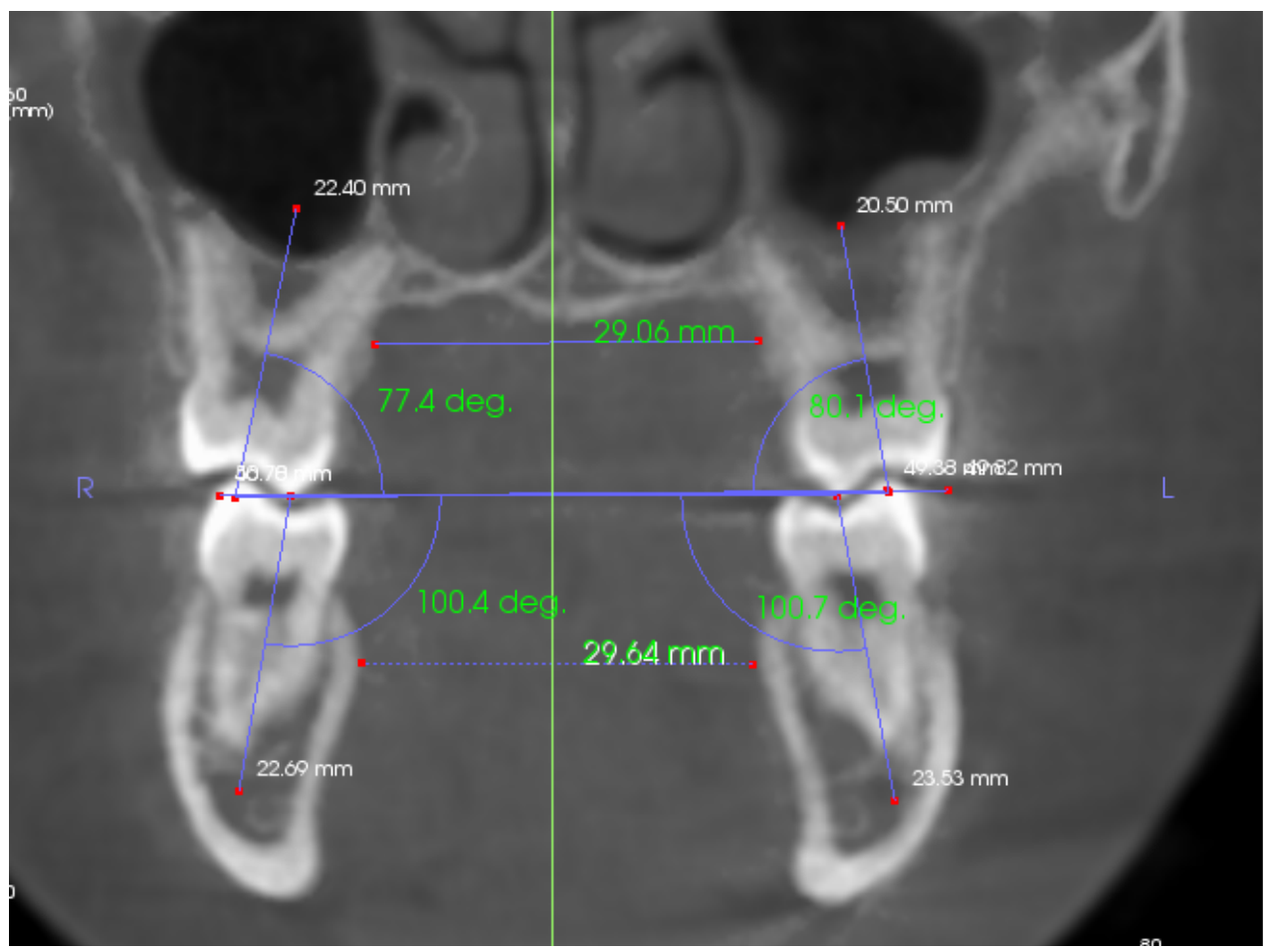

Figure 2: Image of the dental transverse measurements and the molar inclinations as described by Miner.

\section{Condyle and TMJ Analysis:}

Viewed in the axial section, each condyle will have a sagittal section determined by a vertical plane bisecting the long axis. Anterior joint space, superior joint space, and posterior joint space will be measured at the bisected sagittal section and $5 \mathrm{~mm}$ medial and lateral to this section. The angle of the long 
axis of the condyle will be measured from the midsagittal plane. Each joint measurement was made twice over a 2 week period for reliability.

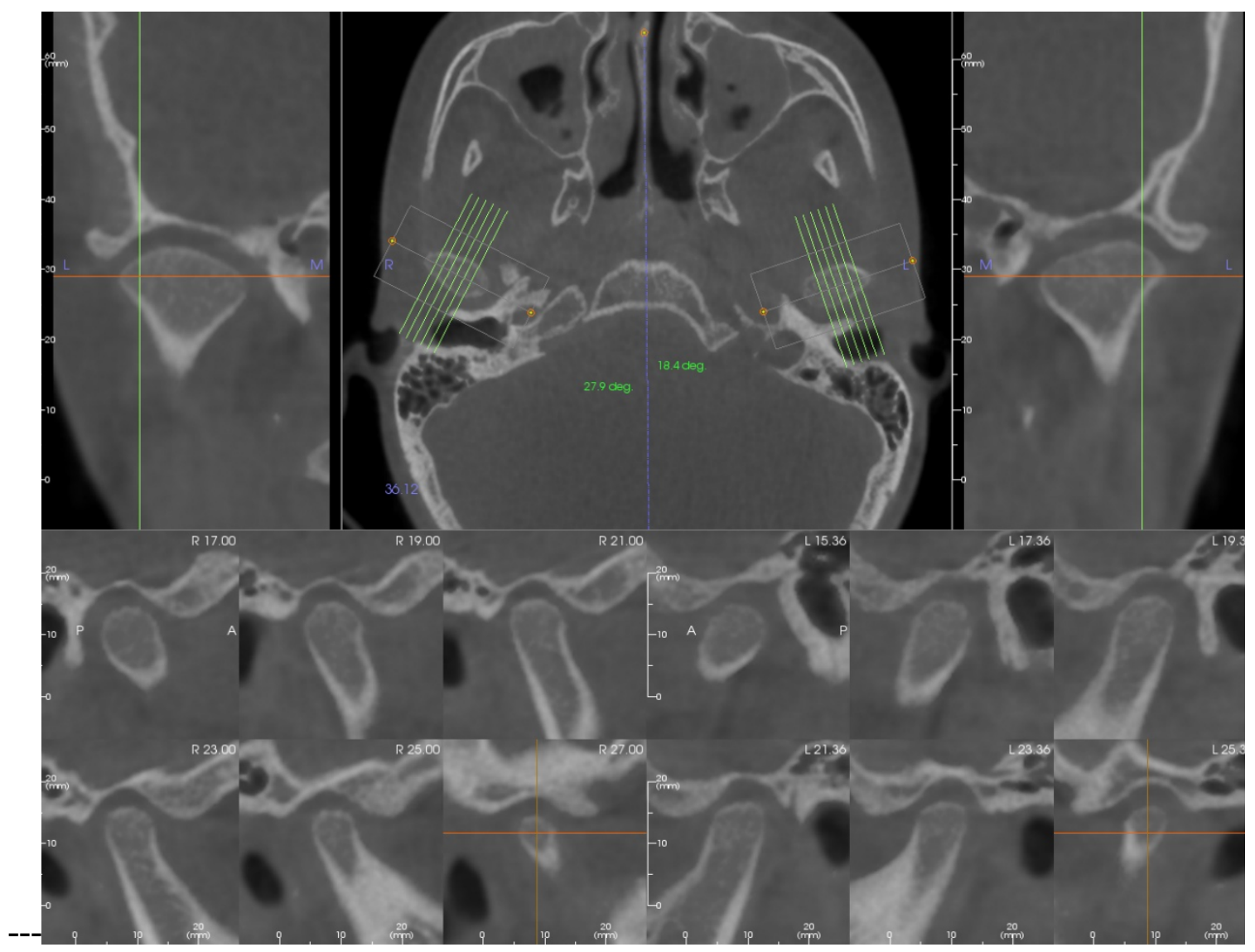

Figure 3: View of the imaging planes for joint space analysis.

Signs of active and reparative progressive condylar resorption and/or degenerative joint disease were recorded. Defects that were visualized were attempted to classify according to the following criteria, flattening, osteophytes, cup shaped defects, cortical surfaces defined but not corticated, and beaking, but due to inadequate image resolution on some images, an exact identification was not always possible. 


\section{Statistical Analysis:}

The mean, standard deviation, and standard error were calculated on all variables measured. A one way group analysis of variance (ANOVA) was used to determine differences between the control and study groups for both Vanarsdall and Miner's transverse analysis, between the crossbite and non crossbite side molar inclinations, between the condyle widths and mid sagittal angles, and between the AS, SS, and PS for the medial pole, center position, and lateral pole of the condyles from the crossbite side to the non crossbite side, and to the controls. Matched t-test was done to determine differences between crossbite and non crossbite sides within the same patient. Pairwise correlations test was performed on all measurements to determine examiner reliability 


\section{Chapter IV - Results}

\section{Study Demographics}

The number of subjects selected was limited to the database of the

Dr. Shipley and was even for both the control and study groups for this research project: 31 subjects were in the control group and 29 subjects were in the study group. A total of 120 TMJ's were analyzed, with 62 of those being control sample TMJs, 29 TMJ's were crossbite side and 29 TMJs were noncrossbite side. Of the 29 crossbite group subjects, 19 had crossbites to the left and 10 had crossbites to the right. To analyze the data within the spreadsheet, all crossbite side values were assigned to the left side and the non crossbite side values were assigned to the right side. It can be seen, from Table 1, that the mean age for the entire study sample was 9.61 years old with a range of 6.39 to 14.23 . The lateral cephalometric analysis shows that the entire study sample had a relatively normal SNA, SNB, ANB, SN-MP, FMA, Upper 1-SN, and IMPA, but the ranges could be quite large. ANB ranged from -3.0 to 9.7 , which states that we had Skeletal Class I, II, and III subjects make up the entire population. The entire study sample also had wide range of mandibular planes, SN-MP ranged from $25.5-43.2$. 


\begin{tabular}{|l|l|l|l|}
\hline & Mean & Min & Max \\
\hline Age Years & $9.61 \pm 1.68$ & 6.39 & 14.23 \\
\hline SNA & $82.2 \pm 3.68$ & 74.4 & 92.0 \\
\hline SNB & $78.6 \pm 3.69$ & 70.8 & 86.6 \\
\hline ANB & $3.6 \pm 2.46$ & -3.0 & 9.7 \\
\hline SN-MP & $33.9 \pm 4.38$ & 25.5 & 43.2 \\
\hline FMA & $24.6 \pm 3.80$ & 17.8 & 32.4 \\
\hline Upper 1-SN & $107.7 \pm 8.15$ & 88.2 & 135.9 \\
\hline IMPA & $92.6 \pm 7.19$ & 76.5 & 110.8 \\
\hline
\end{tabular}

Table 1: Distribution of subject demographics for the entire sample.

Table 2 shows that the demographic distribution for both age and cephalometric skeletal patterns of the control group fell within normal limits, but it also had a wide range, like the entire population.

\begin{tabular}{|l|r|l|l|l|}
\hline Control & & Crossbite & & \\
\hline & \multicolumn{1}{|c|}{ Mean } & & Mean & P-Value \\
\hline Age Years & $9.78 \pm 1.34$ & Age Years & $9.43 \pm 2.00$ & 0.43 \\
\hline SNA & $82.0 \pm 3.75$ & SNA & $82.4 \pm 3.67$ & 0.72 \\
\hline SNB & $78.3 \pm 3.68$ & SNB & $79.0 \pm 3.75$ & 0.50 \\
\hline ANB & $3.7 \pm 1.93$ & ANB & $3.4 \pm 2.96$ & 0.66 \\
\hline SN-MP & $33.4 \pm 3.98$ & SN-MP & $34.4 \pm 4.78$ & 0.37 \\
\hline FMA & $24.1 \pm 3.61$ & FMA & $25.3 \pm 3.98$ & 0.24 \\
\hline Upper 1-SN & $107.6 \pm 9.29$ & Upper 1-SN & $107.8 \pm 6.90$ & 0.95 \\
\hline IMPA & $94.5 \pm 6.79$ & IMPA & $90.5 \pm 7.14$ & $0.03^{*}$ \\
\hline
\end{tabular}

Table 2: Distribution of the Control Group and Distribution of the Crossbite Group

Table 2 also shows that the demographic distribution for the study group was consistent with the control group and the entire study population. The average 
age for the control group was $9.78 \pm 1.34$, and the average age for the crossbite group was $9.43 \pm 2.00$. The average ANB of the control group was $3.7 \pm 1.93$, and the average ANB of the crossbite group was $3.4 \pm 2.96$. The average SNMP for the control group was $33.4 \pm 3.98$, and the average SN-MP for the crossbite group was $34.4 \pm 4.78$. For age and skeletal morphologies, the groups were statistically similar.

\section{$\underline{\text { Transverse Measurements }}$}

When comparing the tranverse differential index from Table 3, there were no significant differences between the control and crossbite groups. There were very slight trends between the means of the two groups. The mandibular width, AG-GA, of the crossbite group was slightly larger than that of the control group. The maxillary width, JR-JL, of the crossbite group was slightly smaller than that of the control group. The expected maxillo-mandibular difference was almost identical for the two groups. The actual maxillo-mandibular difference and the transverse differential index between the groups is slightly larger, which is to be expected given the differences in the maxillary and mandibular widths of the study groups.

\begin{tabular}{|l|l|l|l|l|l|}
\hline & Control & & Crossbite & & \\
\hline & Mean & St Error & Mean & St Error & P-Value \\
\hline GA-AG $(\mathrm{mm})$ & $74.75 \pm 3.89$ & 0.68 & $75.43 \pm 3.73$ & 0.71 & 0.49 \\
\hline JR-JL (mm) & $57.89 \pm 2.89$ & 0.48 & $57.00 \pm 2.48$ & 0.50 & 0.21 \\
\hline Exp Mx Md Diff & $14.74 \pm 0.81$ & 0.18 & $14.77 \pm 1.13$ & 0.18 & 0.88 \\
\hline Act. Mx Md Diff & $16.85 \pm 3.71$ & 0.64 & $18.41 \pm 3.35$ & 0.66 & 0.09 \\
\hline TDI & $-2.12 \pm 3.92$ & 0.65 & $-3.64 \pm 3.29$ & 0.67 & 0.11 \\
\hline
\end{tabular}

Table 3: Vanarsdall's Transverse Differential Index 
Table 4 shows the maxillo-mandibular difference with the measurement approach as explained by Miner (18).

\begin{tabular}{|l|l|l|l|l|}
\hline Miner & & & & \\
\hline & & Mean & St Error & P-Value \\
\hline Md Width (mm) & Control & $30.98 \pm 2.48$ & 0.43 & $0.0015^{* * *}$ \\
\hline & Crossbite & $33.03 \pm 2.25$ & 0.44 & \\
\hline Mx Width (mm) & Control & $26.95 \pm 1.76$ & 0.32 & $0.0003^{* * *}$ \\
\hline & Crossbite & $24.81 \pm 2.52$ & 0.47 & \\
\hline Mx-Md Diff (mm) & Control & $-4.01 \pm 2.69$ & 0.51 & $0.0001^{* * *}$ \\
\hline & Crossbite & $-8.22 \pm 3.04$ & 0.53 & \\
\hline
\end{tabular}

Table 4: Miner's Transverse Analysis

The mandibular widths were significantly wider on the crossbite group, $33.03 \pm$ 2.25 , compared the mandibular width of the control group, $30.98 \pm 2.48$, with a pvalue of 0.0015 . The maxillary widths were significantly more narrow on the crossbite group, $24.81 \pm 2.52$, compared the maxillary width of the control group, $26.95 \pm 1.76$, with a $p$-value of 0.0003 . The maxillo-mandibular difference of the crossbite group was $-8.22 \pm 3.04$ compared to the $-4.01 \pm 2.69$ of the control group. The negative value means that the maxillary width is more narrow than the mandibular width. The maxillary width is more narrow than the mandibular width for both the control groups and the crossbite group.

\section{Molar Angle to the Functional Occlusal Plane}

Table 5 shows that there are no significant differences when comparing the control right side to the noncrossbite side upper and lower first molar, and when comparing the control left side to the crossbite side upper and lower first molar. There is a tenancy for the noncrossbite side mandibular molar to be 
inclined slightly more lingually when compared to the right side of the control. There is a tendency for the mandibular molar to be slightly more upright on the crossbite side as compared to the left side of the control. There is also a tendency for the non crossbite side maxillary molar to be slightly more buccally inclined than the right side of the control group.

\begin{tabular}{|l|l|l|l|l|l|}
\hline & Control & & Crossbite & & \\
\hline & Mean & St Error & Mean & $\begin{array}{l}\text { St } \\
\text { Error }\end{array}$ & P-Value \\
\hline Md R 6 Axial & $105.10 \pm 4.50$ & 0.97 & $107.13 \pm 6.22$ & 1.00 & 0.15 \\
\hline Md L 6 Axial & $105.42 \pm 5.33$ & 1.03 & $104.09 \pm 6.11$ & 1.06 & 0.37 \\
\hline Mx R 6 Axial & $80.13 \pm 5.01$ & 0.85 & $78.83 \pm 4.41$ & 0.88 & 0.29 \\
\hline Mx L 6 Axial & $80.05 \pm 6.07$ & 1.09 & $80.31 \pm 4.66$ & 0.86 & 0.86 \\
\hline
\end{tabular}

Table 5: Upper and lower right and left first molar axial inclination to the functional occlusal plane.

Table 6 compares the right to the left molars on the control group and the crossbite group, and it shows there were no difference for either the maxillary or mandibular molars on the control groups. When comparing the mandibular molars for crossbite side to the noncrossbite side, there was a statistically significant difference with the crossbite side molar more upright compared to the non crossbite side, $104.09 \pm 6.11$ to $107.13 \pm 6.22$ respectively. When comparing the maxillary molars, the crossbite side was slightly more upright, $80.31 \pm 4.66$ to $78.83 \pm 4.41$ respectively, but not with any significance. 


\begin{tabular}{|l|l|l|l|l|}
\hline Control & & & & P-Values \\
\hline Md R 6 Axial & $105.10 \pm 4.50$ & Md L 6 Axial & $105.42 \pm 5.33$ & 0.60 \\
\hline Mx R 6 Axial & $80.13 \pm 5.01$ & Mx L 6 Axial & $80.05 \pm 6.07$ & 0.88 \\
\hline Crossbite & & & & \\
\hline Md R 6 Axial & $107.13 \pm 6.22$ & Md L 6 Axial & $104.09 \pm 6.11$ & $0.0024^{* * *}$ \\
\hline Mx R 6 Axial & $78.83 \pm 4.41$ & Mx L 6 Axial & $80.31 \pm 4.66$ & 0.14 \\
\hline
\end{tabular}

Table 6: Compare right and left molar inclination on the same patient

\section{Condyle Size and Orientation}

Table 7 below shows that there are no significant differences between the condyle width and angle to the midsagittal plane. All condyle widths were about the same except the mean crossbite side condyle was about $0.13 \mathrm{~mm}$ more narrow than the rest of the condyles for all groups. Both crossbite side and noncrossbite side condyle were about 0.5 degrees less angulated when compared to the angulation for both condyles of the control group.

\begin{tabular}{|l|l|l|l|l|l|}
\hline & Control & & Crossbite & & \\
\hline & Mean & St Err. & Mean & St Err. & P-Value \\
\hline R Con Width $(\mathrm{mm})$ & $16.54 \pm 1.63$ & 0.31 & $16.53 \pm 1.78$ & 0.32 & 0.99 \\
\hline L Con Width $(\mathrm{mm})$ & $16.54 \pm 1.41$ & 0.28 & $16.40 \pm 1.73$ & 0.29 & 0.75 \\
\hline R Mid Sag Ang & $68.32 \pm 7.78$ & 1.14 & $68.86 \pm 4.38$ & 1.18 & 0.74 \\
\hline L Mid Sag Ang & $68.39 \pm 8.36$ & 1.25 & $68.81 \pm 4.96$ & 1.29 & 0.78 \\
\hline
\end{tabular}

Table 7: Condylar Width and Condylar angle to the midsagittal plane

Table 8 compares the right and left condylar width and midsagittal angle on the same patient. For the control group, the right and left sides for both condylar width, $16.54 \pm 1.63$ and $16.54 \pm 1.41$ respectively, and right and left midsagittal angle, $68.32 \pm 7.78$ and $68.39 \pm 8.36$ respectively, are almost identical. For the Crossbite group, the noncrossbite and crossbite side condylar midsagittal angle, 
$68.86 \pm 4.38$ and $68.81 \pm 4.96$ respectively, were almost identical. The crossbite side condylar width was slightly smaller than the noncrossbite side condyle, $16.40 \pm 1.73$ and $16.53 \pm 1.78$ respectively

\begin{tabular}{|l|l|l|l|l|}
\hline Control & & & & P-Values \\
\hline R Condyle Width & $16.54 \pm 1.63$ & L Condyle Width & $16.54 \pm 1.41$ & 0.99 \\
\hline R Mid Sag Angle & $21.68 \pm 7.78$ & L Mid Sag Angle & $21.69 \pm 8.36$ & 0.99 \\
\hline Crossbite & & & & \\
\hline R Condyle Width & $16.53 \pm 1.78$ & L Condyle Width & $16.40 \pm 1.73$ & 0.07 \\
\hline R Mid Sag Angle & $21.14 \pm 4.38$ & L Mid Sag Angle & $21.19 \pm 4.96$ & 0.93 \\
\hline
\end{tabular}

Table 8: Compare right and left condylar width and midsagittal angle on the same patient.

\section{Condyle Position within Glenoid Fossa}

Table 9 below shows there are no significant differences when comparing the right side joint space of the control group to the noncrossbite side joint space of the crossbite group. When evaluating the center position of the condyle, the AS was slightly smaller for the noncrossbite side, and the PS was slightly larger for the noncrossbite side. When evaluating the medial pole of the condyle the AS and SS are slightly less for the noncrossbite side. The PS was slightly increased for the noncrossbite side. From the lateral pole of the condyle, there were slight increases in the SS and PS of the noncrossbite side condyle. The AS of the lateral pole was almost identical for both groups. 


\begin{tabular}{|l|l|l|l|l|l|}
\hline Right & & & & & \\
\hline Non X-bite & Control & & Crossbite & & P- Value \\
\hline & Mean & St Error & Mean & St Error & \\
\hline Med AS (mm) & $1.80 \pm 0.46$ & 0.10 & $1.62 \pm 0.63$ & 0.10 & 0.21 \\
\hline Med SS (mm) & $2.65 \pm 0.70$ & 0.13 & $2.46 \pm 0.71$ & 0.13 & 0.32 \\
\hline Med PS (mm) & $2.71 \pm 0.91$ & 0.16 & $2.79 \pm 0.89$ & 0.17 & 0.73 \\
\hline Ctr AS (mm) & $\mathbf{1 . 6 8} \pm \mathbf{0 . 4 4}$ & $\mathbf{0 . 4 4}$ & $\mathbf{1 . 5 3} \pm \mathbf{0 . 4 1}$ & $\mathbf{0 . 4 2}$ & $\mathbf{0 . 1 8}$ \\
\hline Ctr SS (mm) & $\mathbf{2 . 4 9} \pm \mathbf{0 . 6 9}$ & $\mathbf{0 . 1 4}$ & $\mathbf{2 . 4 8} \pm \mathbf{0 . 8 1}$ & $\mathbf{0 . 1 4}$ & $\mathbf{0 . 9 9}$ \\
\hline Ctr PS (mm) & $\mathbf{2 . 0 7} \mathbf{0 . 8 4}$ & $\mathbf{0 . 1 9}$ & $\mathbf{2 . 3 4} \pm \mathbf{0 . 2 0}$ & $\mathbf{0 . 2 0}$ & $\mathbf{0 . 3 5}$ \\
\hline Lat AS (mm) & $1.74 \pm 0.83$ & 0.12 & $1.74 \pm 0.52$ & 0.13 & 0.99 \\
\hline Lat SS (mm) & $2.49 \pm 0.83$ & 0.15 & $2.61 \pm 0.87$ & 0.16 & 0.59 \\
\hline Lat PS (mm) & $2.68 \pm 1.10$ & 0.23 & $3.11 \pm 1.47$ & 0.24 & 0.20 \\
\hline
\end{tabular}

Table 9: Measurement of joint spaces for the right of the control compared to the non crossbite side. AS = anterior joint space, SS = superior joint space, and PS = posterior joint space . Med $=$ Medial pole, $\mathrm{Ctr}=$ Central portion, and Lat $=$ lateral pole.

Table 10 shows that there are no significant differences between the any of the crossbite side condylar joint spaces when compare to the left side of the control. When evaluating the center position on the condyle, the AS and SS were slightly decreased, while the PS was slightly increased when compare to the left side of the control group. When evaluating the medial pole, the AS and SS of the crossbite side condyle were slightly smaller, and the PS was almost identical when compared to the left side of the control group. When evaluating the lateral pole, the AS and SS were slightly smaller while the PS was slightly greater on the crossbite side when compared to the left side of the control group. 


\begin{tabular}{|l|l|l|l|l|l|}
\hline Left & & & & & \\
\hline$\underline{\text { X-bite }}$ & Control & & Crossbite & & P- Value \\
\hline & Mean & St Errr & Mean & St Err. & \\
\hline Med AS (mm) & $1.83 \pm 0.65$ & 0.11 & $1.69 \pm 0.62$ & 0.12 & 0.39 \\
\hline Med SS (mm) & $2.58 \pm 0.65$ & 0.14 & $2.43 \pm 0.86$ & 0.14 & 0.47 \\
\hline Med PS (mm) & $2.62 \pm 0.90$ & 0.15 & $2.60 \pm 0.69$ & 0.15 & 0.90 \\
\hline Ctr AS (mm) & $\mathbf{1 . 6 2} \pm \mathbf{0 . 5 2}$ & $\mathbf{0 . 1 0}$ & $\mathbf{1 . 4 7} \pm \mathbf{0 . 6 0}$ & $\mathbf{0 . 1 0}$ & $\mathbf{0 . 3 0}$ \\
\hline Ctr SS (mm) & $\mathbf{2 . 5 2 \pm 0 . 7 8}$ & $\mathbf{0 . 1 4}$ & $\mathbf{2 . 4 2} \pm \mathbf{0 . 8 2}$ & $\mathbf{0 . 1 5}$ & $\mathbf{0 . 6 3}$ \\
\hline Ctr PS (mm) & $\mathbf{2 . 0 7} \pm \mathbf{0 . 7 4}$ & $\mathbf{0 . 1 3}$ & $\mathbf{2 . 0 9} \pm \mathbf{0 . 6 7}$ & $\mathbf{0 . 1 3}$ & $\mathbf{0 . 9 2}$ \\
\hline Lat AS (mm) & $2.01 \pm 0.53$ & 0.12 & $1.72 \pm 0.71$ & 0.13 & 0.08 \\
\hline Lat AS (mm) & $2.59 \pm 0.65$ & 0.13 & $2.29 \pm 0.76$ & 0.13 & 0.10 \\
\hline Lat PS (mm) & $2.51 \pm 0.94$ & 0.18 & $2.61 \pm 1.05$ & 0.19 & 0.70 \\
\hline
\end{tabular}

Table 10: Measurement of joint spaces for the left of the control compared to the crossbite side. AS = anterior joint space, $\mathrm{SS}=$ superior joint space, and PS = posterior joint space . Med $=$ Medial pole, $\mathrm{Ctr}=$ Central portion, and Lat $=$ lateral pole.

Table 11 compares the joint spaces of the right and the left sides of the control groups. There was a significant difference between the AS of the lateral pole, with the right side being smaller than the left, $1.74 \pm 0.83$ and $2.01 \pm 0.53$ respectively. When evaluating the medial pole of the condyle, the left SS was slightly larger while the left PS was slightly smaller. When evaluating the center position of the condyles the joint spaces for AS, SS, and PS were almost very similar. 


\begin{tabular}{|l|l|l|l|}
\hline Control & Right & Left & P-Value \\
\hline R Med AS - L Med AS & $1.80 \pm 0.46$ & $1.83 \pm 0.65$ & 0.74 \\
\hline R Med SS - L Med SS & $2.65 \pm 0.70$ & $2.58 \pm 0.65$ & 0.61 \\
\hline R Med PS - L Med PS & $2.71 \pm 0.91$ & $2.62 \pm 0.90$ & 0.43 \\
\hline R Ctr AS - L Ctr AS & $\mathbf{1 . 6 8} \pm \mathbf{0 . 4 4}$ & $\mathbf{1 . 6 2} \pm \mathbf{0 . 5 2}$ & $\mathbf{0 . 5 4}$ \\
\hline R Ctr SS - L Ctr SS & $\mathbf{2 . 4 9} \pm \mathbf{0 . 6 9}$ & $\mathbf{2 . 5 2} \pm \mathbf{0 . 7 8}$ & $\mathbf{0 . 8 2}$ \\
\hline R Ctr PS - L Ctr PS & $\mathbf{2 . 0 7 \pm \mathbf { 0 . 8 4 }}$ & $\mathbf{2 . 0 7} \pm \mathbf{0 . 7 4}$ & $\mathbf{0 . 9 7}$ \\
\hline R Lat AS - L Lat AS & $1.74 \pm 0.83$ & $2.01 \pm 0.53$ & $0.02^{*}$ \\
\hline R Lat SS - L Lat SS & $2.49 \pm 0.83$ & $2.59 \pm 0.65$ & 0.39 \\
\hline R Lat PS - L Lat PS & $2.68 \pm 1.10$ & $2.51 \pm 0.94$ & 0.27 \\
\hline
\end{tabular}

Table 11: Compare the right side condyle joint spaces to the left condyle joint spaces in the control group.

Table 12 compared the crossbite and noncrossbite side condylar spaces to each other. The only significant difference was between the SS of the lateral pole, with the crossbite side smaller, $2.29 \pm 0.76$ compared to $2.61 \pm 0.87$ of the noncrossbite side. The medial pole of the condyle on the crossbite side PS was slightly smaller than the noncrossbite side. The AS and SS were very similar. The center of the condyle's AS and SS were very similar, and the PS was slightly greater on the crossbite side.

\begin{tabular}{|l|l|l|l|}
\hline Crossbite & & & \\
\hline & Non X-bite & X-Bite & Crossbite \\
\hline R Med AS - L Med AS & $1.62 \pm 0.63$ & $1.69 \pm 0.62$ & 0.40 \\
\hline R Med SS - L Med SS & $2.46 \pm 0.71$ & $2.43 \pm 0.86$ & 0.82 \\
\hline R Med PS - L Med PS & $2.79 \pm 0.89$ & $2.60 \pm 0.69$ & 0.06 \\
\hline R Ctr AS - L Ctr AS & $\mathbf{1 . 5 3} \pm \mathbf{0 . 4 1}$ & $\mathbf{1 . 4 7} \pm \mathbf{0 . 6 0}$ & $\mathbf{0 . 4 8}$ \\
\hline R Ctr SS - L Ctr SS & $\mathbf{2 . 4 8} \pm \mathbf{0 . 8 1}$ & $\mathbf{2 . 4 2} \pm \mathbf{0 . 8 2}$ & $\mathbf{0 . 6 7}$ \\
\hline R Ctr PS - L Ctr PS & $\mathbf{2 . 3 4} \pm \mathbf{0 . 2 0}$ & $\mathbf{2 . 0 9} \pm \mathbf{0 . 6 7}$ & $\mathbf{0 . 2 3}$ \\
\hline R Lat AS - L Lat AS & $1.74 \pm 0.52$ & $1.72 \pm 0.71$ & 0.90 \\
\hline R Lat SS - L Lat SS & $2.61 \pm 0.87$ & $2.29 \pm 0.76$ & $0.04^{*}$ \\
\hline R Lat PS - L Lat PS & $3.11 \pm 1.47$ & $2.61 \pm 1.05$ & 0.60 \\
\hline
\end{tabular}


Table 12: Compare the noncrossbite side condyle joint spaces to the crossbite condyle joint spaces.

\begin{tabular}{|l|l|l|l|}
\hline \multicolumn{2}{|l|}{ Reliability Coefficient } & & \\
\hline RM AS & 0.98 & LM AS & 0.98 \\
\hline RM SS & 0.98 & LM SS & 0.99 \\
\hline RM PS & 0.99 & LM PS & 0.99 \\
\hline RC AS & 0.96 & LC AS & 0.98 \\
\hline RC SS & 0.98 & LC SS & 0.98 \\
\hline RC PS & 0.99 & LC PC & 0.98 \\
\hline RL AS & 0.98 & LL AS & 0.98 \\
\hline RL SS & 0.99 & LL SS & 0.98 \\
\hline RL PS & 0.99 & LL PS & 0.97 \\
\hline
\end{tabular}

Table 13: Reliability Coefficients of all joint space measurements.

Table 13 shows the pairwise correlation that was performed on all joint space measurements two weeks apart. The two lowest values were for the right condyles center AS at 0.96 and the left condyle's lateral PS at 0.97 . The rest had valued of 0.98 or 0.99 .

A qualitative analysis of the condyles measured identified when a radiographic sign of joint disease was present. For the control group 19 of 31 subjects had a radiographic sign present, 2 of those 19 had a sign on right only, 4 of 19 on left only, and 13 of 19 had a sign bilaterally. For the crossbite group 21 of the 29 subjects had a radiographic sign present, 9 of the 21 had a sign on the crossbite side only, 6 of 21 on the noncrossbite side only, and 6 of 21 had a sign bilaterally. Signs included the following flattening on anterior, superior, or posterior parts of the medial, central, and/lateral poles, beaking, cortical irregularities, osteophytes, and cupping. 


\section{Chapter V - Discussion}

\section{Imaging}

The TMJ's are a unique joint and their anatomical position makes it difficult to evaluate with traditional radiography. CT imaging is one of the leading methods for evaluating the TMJs. There are many different types of CT scans including linear or complex motion CT, helical or multi-slice CT, or CBCT. Tsiklakis, et al. showed that CBCT images are of high diagnostic quality, and are recommended to be the technique of choice when investigating boney changes

of the TMJ (49). Suomalainen, et al. showed error of linear measurements using CBCT was less than linear measurements of multislice CBCT (75). Kobayashi, et al. reported that measurement error was significantly less with CBCT than spiral CBCT (76). In 2008, Honda, et al showed that bone thickness measurement was accurate and effective with limited cone beam x-ray CT. They concluded that $\mathrm{CBCT}$ allows accurate morphologic assessment of the boney structures of the TMJ (77). Every joint was measured twice in this study to determine the reliability with these measurements using СВCT images. The Pairwise Correlation test showed there was a high reliability for all the measurements. This coincides with previous studies showing high accuracy in measurements (77). The largest downside to CT imaging of the TMJ, is that it cannot image the soft tissue structures, mainly the articular disc. 


\section{Study Demographics}

This study focused its attention on subjects in the mixed dentition to early permanent dentition stages, and wanted to determine if the presence of a unilateral posterior crossbite with a functional shift alone could alter the position of the condyles within the glenoid fossa. The mean age of the control group was 9.78 with a range of 6.69 to 12.74 years old. The mean age of the crossbite group was 9.43 with a range of 6.39 to 14.23 . The mean ANB of the control group was 3.7 with a range of -0.3 to 6.8 , and the mean ANB of the crossbite group was 3.4 with a range of -3.0 to 9.7 . The means of both the control and the crossbite group were similar, but the crossbite group showed a larger range. It would have been ideal to have the ANB's of both the control and the crossbite groups to have nearly identical values to eliminate any skeletal disparities between the groups even though they are statistically different. It has been documented that skeletal pattern can effect the position of the condyles within the glenoid fossa $(78,79)$. The mean SN-MP angle for the control group was 33.4 with a range of 26.8 to 41.4 , and the mean SN-MP for the crossbite group was 34.4 with a range of 25.5 to 43.2 . The crossbite side has a slightly larger range for the mandibular plane angle, but the groups are very similar. No studies were found to evaluate the direct impact of mandibular growth direction, either vertical or horizontal, on the position of the condyles within glenoid fossa. It was advantageous for this study that the skeletal patterns and age were consistent between groups because any significant difference in variables could have indirectly affected the results found between the control and crossbite groups. 


\section{$\underline{\text { Transverse Analysis }}$}

This study evaluated the transverse dimension by two different methods. The first was the traditional method using a posterior-anterior cephalogram and points from Rickett's analysis (7). Vanarsdall had described this method as the Transverse Differential Index, and it is a well accepted method for evaluating the skeletal maxillary and mandibular widths using PA cephs (8). The TDI was used to evaluate the subjects as done historically. This measures the maxillary width as jugale right to jugale left and the mandibular width as antegonial right to antegonial left. From those measurements the actual maxillomandibular difference was calculated. An estimated maxillomandibular difference was calculated from norms bases on growth associated with age. You would subtract the two and that would give the transverse differential index (TDI). The TDI is useful because it give a relative measure of the maxillomandibular deficiency regardless of age. This study had a maxillary width for the control and the crossbite group at $57.89 \pm 2.89$ and $57.00 \pm 2.48$ respectively. This study had a mandibular width for the control and the crossbite group at $74.75 \pm 3.89$ and $75.42 \pm 3.73$ respectively. In 1996, Brin, et al. did a study evaluating the transverse dimension in patients in the mixed dentition with a unilateral posterior crossbite with a functional shift using the same analysis (80). Their study found the maxillary width for the crossbite group was reduced at $52 \mathrm{~mm}$, which was reduced more than ours at $57.00 \mathrm{~mm}$. The mandibular width was $76 \mathrm{~mm}$ while ours was similar at $75.42 \mathrm{~mm}$. It was determined that by using an expansion 
appliance the growth of the transversely deficient maxilla was positively affected well beyond what could be expected from normal growth.

The actual maxillomandibular difference of the control group was $16.85 \pm$ 3.71 and the difference for the crossbite group was $18.41 \pm 3.35$. There was no statistical significance between the two. The expected maxillomandibular differences were almost identical which would be expected since the two study groups had similar demographics. The control was $14.74 \pm 0.81$ and the crossbite was $14.77 \pm 1.13$. The TDI of the control group was $-2.12 \pm 3.92$, and the TDI of the crossbite group was $-3.64 \pm 3.29$. There was no significance but the crossbite group had a slightly higher maxillomandibular difference as indicated by the TDI.

Miner, et al. was one of the first to publish a study measuring the palatal and lingual widths on a CBCT image. This method of measurement was used to evaluate the maxillary and mandibular alveolar widths based on CBCT images, and transverse dimensions have not been studied extensively using CBCT images. Our maxillary (palatal) width was $26.95 \mathrm{~mm} \pm 1.76$ for the control group compared to $27.73 \mathrm{~mm} \pm 2.08$ from Miner. Our maxillary width for the crossbite group was $24.81 \mathrm{~mm} \pm 2.52$ compared to $26.43 \mathrm{~mm} \pm 2.12$ from Miner. Our mandibular (lingual) width for the control group was $30.98 \mathrm{~mm} \pm 2.48$ compared to $28.95 \mathrm{~mm} \pm 2.79$ from Miner. Our mandibular width for the crossbite group was $33.03 \mathrm{~mm} \pm 2.25$ compare to $32.35 \mathrm{~mm} \pm 2.75$ from Miner. Our control maxillomandibular difference was $-4.01 \mathrm{~mm} \pm 2.69$ compared to $-1.22 \pm 2.91$ from 
Miner, and our crossbite maxillomandibular difference was $-8.02 \mathrm{~mm} \pm 3.04$ compared to $-4.38 \pm 7.06$ from Miner (18).

\section{Molar Angle to the Functional Occlusal Plane}

Most all unilateral posterior crossbites with a functional shift are a result of a symmetrically deficient maxilla tranversly. Dental compensation is often observed in the form of molar tipping either buccally or lingually, on the noncrossbite side compare to the crossbite side. Our study wanted to determine if the crossbite side molars showed less dental compensation compared to the noncrossbite side, which is similar to results found by Miner. For the control groups, our maxillary molars were inclined $80.13 \pm 5.01$ and $80.05 \pm 6.07$. Our maxillary molars were inclined more buccally when compared to the maxillary molar inclination 97.99 and 98.29 as published by Miner. For the control group our mandibular molars were inclined $105.10 \pm 4.50$ and $105.42 \pm 5.33$ compared to the 103.85 and 104.44 as published. For the crossbite groups our maxillary molars were inclined $78.83 \pm 4.41$ for the noncrossbite side and $80.31 \pm 4.66$ for the crossbite side, compared to their respective inclinations of 101.51 noncrossbite side and 96.98 crossbite side as published. For the crossbite group our mandibular molars were inclined $107.13 \pm 6.22$ on the noncrossbite side and $104.09 \pm 6.11$ on the crossbite side, compared to 105.93 noncrossbite side and 99.81 crossbite side as published (18). It is unclear as to why there was a substantial difference between our maxillary molar inclination and Miner's maxillary molar inclination. Our maxillary molars were slightly buccally inclined, 
but from the numbers, it appears that Miner's maxillary molars were lingually inclined. Based on the appearance of the measurements, the measurements were believed to be taken in a similar fashion between both studies.

\section{Condylar Size and Orientation}

The angulation of the condyles for both the control and the crossbite group were not statistically significant. The control group was angulated 68.32 for the right side and 68.31 for the left to the midsagittal plane, and the crossbite group was angulated 68.86 for the noncrossbite and 68.81 for the crossbite side. The right and left condylar widths in the current study were both measured at 16.54 for the control group and the widths for the crossbite group was 16.53 for the noncrossbite side and 16.40 for the crossbite side. Two studies published by Vitral, et al. in 2002 and 2004 measured the condylar angle and width. Condylar angle to the midsagittal plane was found to be 64.73 and 65.77 , which is slightly more angulated than what was found in the current study. Condylar widths were 17.83 and 17.68 , which was slightly higher than in our group, but they studied an older population ranging from 12.8-42 years old with a Class II Div 2 morphology $(81,82)$.

\section{$\underline{\text { Joint Space }}$}

This study attempted to evaluate the relationship of the medial, central, and lateral sections of the condyles to the glenoid fossa, even though Ikeda showed landmark identification became more difficult in the lateral areas of the 
condyle (53). Part of this theory was based upon a study done by Christiansen, et al. that found the anterosuperior joint space was consistent across the joint when the disc was properly positioned within the joint (83). Hansson, et al., 1977, measured disc thickness upon autopsy of subjects ranging from 1 day to 93 years old. It was observed the anterior band was $2.0 \mathrm{~mm}$ thick, the intermediate band was $1.1 \mathrm{~mm}$ thick, and the posterior band was $2.9 \mathrm{~mm}$ thick. (84).

When evaluating the center position of the condyles only, this study found that the values for the control group were relatively similar to crossbite group. The main differences observed were for the AS for both crossbite and noncrossbite sides, for the SS of the crossbite side, and the PS of the noncrossbite side. The AS for both sides was slightly reduced compared to the control groups. The SS for the crossbite side was slightly reduced compared to the control side and it hints at a small tendancy for the condyle to be more superior in the glenoid fossa. The PS for the non crossbite side was slightly increased compared to the control sides and it also hints at a small tendancy for the condyle to be more anteriorly positioned on the noncrossbite side.

Ikeda used limited view CBCT and found that the AS was 1.3, SS was 2.5, and the PS was 2.1(53). When those values were compared to those of Kinniburgh, they were found to be smaller, but Ikeda believe that their values indicated a smaller range for optimally healthy joints, even though Kinniburgh used MRI analysis to determine healthy from pathologic joints. Kinniburgh did not use as rigorous a method to classify the healthy or optimal joints $(53,85)$. 
Kinniburgh used MRI and tomograms to evaluate the condyles in normal patients and those with anteriorly displaced discs, and they found that the anterior joint space was 1.92 , the superior joint space was 3.62 , and the posterior joint space was 2.95 (85). Major, et al., in 2002, used MRI and tomograms to study joint position and they found that osseous adaptations occur within the TMJ if internal derangements are present and that disc displacement is associated with a reduced joint space (86). Katsavrias and Halazonetis, in 2005, using axially corrected tomograms found that class III subjects had a more elongated and anteriorly inclined condylar head and a wider and more shallow fossa. In the Class III group, the condyle was closer to the roof of the fossa. The Class II Division 1 and Division 2, differed only in the position of the condyle. The condyle of the Class II Div 2 was situated more anteriorly in the fossa. (87) In 2012, Leonardi, et al. performed a low dose CT study analyzing the crossbite and noncrossbite side condyles pretreatment and post treatment. There were no differences in position of the condyles pre-treatment, but they measured significant increases in superior joint space post-treatment on the noncrossbite side, and relative increases in anterior and posterior joint spaces on the noncrossbite sides. The posterior joint space increased only on the crossbite side post treatment (66). Lam, et al. used horizontally corrected tomograms and found large standard deviations resulting in the inability to detect any significant differences within or between groups (88).

Vitral, et al., in 2002 and 2004, studied the TMJ of Class II Div I patients for condylar symmetry and condylar-fossa relationship using computed 
tomography. The anterior joint space was measured at 1.32 and 1.23 per side, the superior joint space was 1.29 and $1.41 \mathrm{~mm}$ per side, and the posterior joint space 1.86 and 1.85 per side in their study. Their study did not use the same methodology when selecting the points for joint space measurement as was selected in our study $(81,82)$. In another study published in 1987, Christiansen, et al. measured the anterior superior joint space was as $1.7 \mathrm{~mm}$, while the central superior joint space was $2.2 \mathrm{~mm}$. This study was completed with temporal bone CT scans and was also limited to those without clinical or radiographic signs of TMD (89).

Rodrigues, et al. has published papers discussing a topic called condylar concentricity. Condylar concentricity simply means that the condyle is in the exact middle of the glenoid fossa. This would not be expected because the thinnest part of the articular disc lies at the anterior-superior portion of the condyle. They determined the sagittal slice allows for the best measurement of condylar concentricity as opposed to other views. Rodrigues, et al., in 2009, used CT imaging to measure joints in Class I, Class II Div I, and Class III patients. In Class I subjects an anterior joint space of 1.29 and 1.22, a superior joint space of 1.57 and 1.59 , and a posterior joint space of 1.87 and 1.65 was measured. In Class II Div I subjects an anterior joint space of 1.28 and 1.11, a superior joint space of 1.62 and 1.66 , and a posterior joint space of 2.38 and 2.16 was observed. In Class III subjects they found an anterior joint space of 1.25 and 1.23 , a superior joint space of 1.86 and 1.64 , and a poster joint space of 2.21 and 1.99. The condyles in the Class II Div I and the Class III subjects were more 
anteriorly placed than the Class I subjects. They did not find condylar concentricity within any of the groups $(78,79)$.

The thought that the condyles are asymmetrically positioned, with the crossbite side being more anterior and inferior within the glenoid fossa was not confirmed by this present study. Prior studies using transcranial radiography and tomography have documented that the positioning of the condyles is asymmetric from the crossbite to noncrossbite side $(43,60,64)$. Cohlmia, et al., in 1996, used corrected tomograms to study Class I, II and III subjects and found that the right and left joints were frequently not in the same position within the glenoid fossa. They found the left to be more anteriorly positioned than the right, and that subjects with a skeletal and dental Class III demonstrated more anteriorly positioned condyles. Differences in the skeletal or dental Class I or II groups, were not observed and the presence of an overbite or a crossbite did not impact results (90). In 2008, Kilic, et al. evaluated panoramic and lateral cephalometric radiographs and determined that the patients with unilateral posterior crossbite had more asymmetric condyles on the crossbite side, and the condylar, ramal, and condylar-plus-ramal heights on the crossbite side were smaller than the noncrossbite side (91).

From studies more recently published, it has been found that positional differences between crossbite and noncrossbite side condyles is not present pre treatment in patients with a unilateral posterior crossbite with a functional shift. A strong theory behind the symmetry found in joint spaces on crossbite and noncrossbite sides recorded before treatment could be explained by 
compensatory condyle fossa remodeling and/or variation in thickness of the articular TMJ disc as described by Hesse, et al. and Wang, et al. (43, 92). Wang suggested that the TMJ disc has the ability to adapt to any alteration caused by occlusal changes occurring in the space between the condyle and fossa (92). Myers, et al. also concluded there is the potential for adaptive growth changes to occur if the mandibular shifting occurred resulting from malocclusion (60).

The present study noticed a wide range of signs of progressive condylar resorption inclucing erosions, sclerosing, flattening, cupping and osteophytes on both sides of the control and crossbte study groups. Yamada, et al. in 2004, studied subjects with and without TMD signs and/or symptoms who were about to undergo orthognathic surgery. Their results suggested that eminence flattening might occur as a result of TMJ changes from erosion to osteophyte formation and from anterior disc displacement with reduction to antererior disc displacement without reduction (93).

The only significant difference that was found in joint space was found between the right and left sides AS of the lateral pole on the control group and between the crossbite and noncrossbite sides of the SS of the lateral pole on the crossbite group. The difficulty in skeletal anatomy and morphology at the lateral pole of the condyle made measurement difficult and the difference is likely attributed to the wide anatomical differences found between the individual subjects of the entire group. It does not seem to be advisable to continue to measure joint spaces at lateral pole of the condyle in this similar fashion. 
Radiography is not the only method being used to evaluate condylar position. Masi, et al., in 2009, treated subjects with unilateral posterior crossbite with a functional shift, and evaluated the disc in those subjects pre-treatment, after expansion therapy, and 9 months post-treatment with MRIs in a close mouth and open mouth positions. They did not find any changes in the articular disc position or configuration in over $95 \%$ of the subjects (94). Pellizoni, et al. used MRI to evaluate the position and configuration of the articular disc in those with and without a FUPXB, and all of their subjects had asymptomatic joints. No differences in disc position or morphology were found except that one joint in the control and one joint in the shift group with a folded disc (65).

In an attempt to limit the use of x-rays to analyze the condylar position, Lippold, et al. used an ultrasonic ARCUS $®$ digma system. They studied a control and a unilateral posterior crossbite with a functional shift, and did not find any significant difference between the initial pretreatment groups (95).

\section{Limitations:}

The dental history findings, regarding TMJ status, were occasionally missing or incomplete preventing an accurate determination of the joint health upon clinical investigation. The clinical examination is not adequate method alone for evaluating TMJ status, but it provides for a baseline from where further analysis can initiate. Having a wide range of skeletal morphologies and age groups could have added unaccounted variables potentially affecting the results. The positioning of the subjects within the CBCT machine was not performed by a 
single operator. Positioning for our study was based upon Frankfort's horizontal, as done in Leonardi's study, while Ikeda paralleled the transverse plane from superior points of the external auditory meatus and the glenoid fossa. 


\title{
Chapter VI - Summary and Conclusion
}

\author{
After evaluating all the variables measured, the most remarkable \\ difference found was the maxillary (palatal) and mandibular (lingual) widths when \\ comparing the control and the crossbite group. Our study population did not find \\ a skeletal significant difference between the maxillomandibular skeletal \\ measurements, but found an $8 \mathrm{~mm}$ maxillomandibular difference when measuring \\ by the method described by Miner's approach. Ultimately there were no \\ significant differences in joint space found between any of the groups with the \\ exception of the AS of the lateral pole for the control group and the SS of the \\ lateral pole of the crossbite group. Since there were no positional differences in \\ the condyle between the control and crossbite groups, some sort of remodeling \\ that occurs within the TMJ would likely have to occur. The null hypotheses \\ accepted were:
}

1. There is no difference in the maxillary and mandibular transverse dimensions by the Vanarsdall approach in the study compared to the control in untreated orthodontic patients.

3. There is no difference in the angle of the maxillary and mandibular first molars between the study and control groups, and between the crossbite and non crossbite sides of the study group.

4. There is no difference in the width of right and left condyles in the study compared to the control. 
5. There will be no difference in the condylar angle to the midsaggital plane between the control and the study groups, and between the crossbite and non crossbite sides of the study group.

6. There will be no difference in position of condyles in the TMJ, when comparing similar points, between the control and the study groups, and between the crossbite and non crossbite sides of the study group.

a. For All but crossbite side and noncrossbite side lateral SS in the crossbite group, and the right and left lateral AS of the control group.

7. There will be no difference in the signs of osseous changes of the control group to the study group

The rejected null hypothesis were:

2. There is no difference the maxillary and mandibular transverse dimensions by the Miner approach in the study compared to the control.

6. There will be no difference in position of condyles in the TMJ, when comparing similar points, between the control and the study groups, and between the crossbite and non crossbite sides of the study group.

a. For all but crossbite side and noncrossbite side lateral SS in the crossbite group, and the right and left lateral AS of the control group. 


\section{Chapter VII - Recommendations for Future}

\section{Research}

It is important to compare the changes that occur in any one joint before and after unilateral posterior crossbite correction. Future research can repeat this study to determine if age, gender, ethnicity, or skeletal morphology result in different outcomes. In order for an accurate determination of the effects of unilateral posterior crossbite with a functional on the joints, the conditions or parameters of healthy joints for varying skeletal patterns needs to be clearly identified. Future research could evaluate the occurrence of radiographic joint pathology in asymptomatic normal patients, and those with unilateral posterior crossbite with a functional shift. Also, An analysis on the severity and staging of radiographic signs of TMD on a normal compared to unilateral posterior crossbite with a functional shift could be done. 


\section{References}

1. Enlow DH, Hans M. Essentials of facial growth. Second Edition ed. Enlow DH and Hans M, editors. Ann Arbor, MI: Needham Press, Inc.; 2008.

2. Björk A. Prediction of mandibular growth rotation. Am J Orthod. 1969 06;55(6):585-99.

3. Gu Y, McNamara JA. Mandibular growth changes and cervical vertebral maturation. a cephalometric implant study. Angle Orthod. 2007 11;77(6):947-53.

4. Okeson JP. Functional anatomy and biomechanics of the masticatory system. In: Okeson JP, editor. Management of Temporomandibular Disorders and Occlusion. 5th ed. St. Louis, Mo.: Mosby; 2003. p. 6-26.

5. Howe RP, McNamara JA, J., O'Connor,K.A. An examination of dental crowding and its relationship to tooth size and arch dimension. Am J Orthod. 1983 05;83(5):363-7.

6. Fifty years of cephalometric radiography. Angle Orthod. 1981 04;51(2):88-171. 7. Ricketts RM. Perspectives in the clinical application of cephalometrics. the first fifty years. Angle Orthod. 1981 04;51(2):115-50.

8. Vanarsdall RL, J. Transverse dimension and long-term stability. Semin Orthod. 1999 09;5(3):171-80.

9. THUROW RC. Cephalometric methods in research and private practice. Angle Orthod. 1951 04;21(2):104-16.

10. Major PW, Johnson DE, Hesse KL, Glover KE. Landmark identification error in posterior anterior cephalometrics. Angle Orthod. 1994;64(6):447-54. 
11. Major PW, Johnson DE, Hesse KL, Glover KE. Effect of head orientation on posterior anterior cephalometric landmark identification. Angle Orthod. 1996;66(1):51-60.

12. Yoon Y, Kim D, Yu P, Kim H, Choi E, Kim K. Effect of head rotation on posteroanterior cephalometric radiographs. Angle Orthod. 2002 02;72(1):36-42. 13. Ghafari J, Cater PE, Shofer FS. Effect of film-object distance on posteroanterior cephalometric measurements: Suggestions for standardized cephalometric methods. Am J Orthod Dentofacial Orthop. 1995 07;108(1):30-7. 14. Huang J, Bumann A, Mah J. Three-dimensional radiographic analysis in orthodontics. J Clin Orthod. 2005 07;39(7):421-8.

15. Mah J, Hatcher D. Current status and future needs in craniofacial imaging. Orthod Craniofac Res. 2003;6 Suppl 1:10-6.

16. Lascala CA, Panella J, Marques MM. Analysis of the accuracy of linear measurements obtained by cone beam computed tomography (CBCT-NewTom). Dentomaxillofac Radiol. 2004 09;33(5):291-4.

17. Lamichane M, Anderson NK, Rigali PH, Seldin EB, Will LA. Accuracy of reconstructed images from cone-beam computed tomography scans. Am J Orthod Dentofacial Orthop. 2009 08;136(2):156.e.

18. Miner RM, Al Qabandi S, Rigali PH, Will LA. Cone-beam computed tomography transverse analysis. part I: Normative data. Am J Orthod Dentofacial Orthop. 2012 09;142(3):300-7. 
19. Heikinheimo K, Salmi K, Myllärniemi S. Long term evaluation of orthodontic diagnoses made at the ages of 7 and 10 years. Eur J Orthod. 1987 05;9(2):1519.

20. Thilander B, Wahlund S, Lennartsson B. The effect of early interceptive treatment in children with posterior cross-bite. Eur J Orthod. 1984 02;6(1):25-34. 21. Leighton BC. Symposium on aspects of the dental development of the child. 2. the early development of cross-bites. Dent Pract Dent Rec. 1966 12;17(4):14552.

22. Kurol J, Berglund L. Longitudinal study and cost-benefit analysis of the effect of early treatment of posterior cross-bites in the primary dentition. Eur $\mathrm{J}$ Orthod. 1992 06;14(3):173-9.

23. Infante PF. An epidemiologic study of finger habits in preschool children, as related to malocclusion, socioeconomic status, race, sex, and size of community. ASDC J Dent Child. 1976 1976;43(1):33-8.

24. Kutin G, Hawes RR. Posterior cross-bites in the deciduous and mixed dentitions. Am J Orthod. 1969 11;56(5):491-504.

25. Thilander B, Lennartsson B. A study of children with unilateral posterior crossbite, treated and untreated, in the deciduous dentition--occlusal and skeletal characteristics of significance in predicting the long-term outcome. J Orofac Orthop. 2002 09;63(5):371-83.

26. Foster TD, Day AJ. A survey of malocclusion and the need for orthodontic treatment in a shropshire school population. Br J Orthod. 1974 04;1(3):73-8. 
27. Fuentes MA, Opperman LA, Buschang P, Bellinger LL, Carlson DS, Hinton RJ. Lateral functional shift of the mandible: Part I. effects on condylar cartilage thickness and proliferation. Am J Orthod Dentofacial Orthop. 2003 02;123(2):153-9.

28. Infante PF. Malocclusion in the deciduous dentition in white, black, and apache indian children. Angle Orthod. 1975 07;45(3):213-8.

29. Schröder U, Schröder I. Early treatment of unilateral posterior crossbite in children with bilaterally contracted maxillae. Eur J Orthod. 1984 02;6(1):65-9. 30. Modéer T, Odenrick L, Lindner A. Sucking habits and their relation to posterior cross-bite in 4-year-old children. Scandinavian Journal of Dental Research. 1982 08;90(4):323-8.

31. Ogaard B, Larsson E, Lindsten R. The effect of sucking habits, cohort, sex, intercanine arch widths, and breast or bottle feeding on posterior crossbite in norwegian and swedish 3-year-old children. Am J Orthod Dentofacial Orthop. 1994 08;106(2):161-6.

32. Subtelny JD. Oral respiration: Facial maldevelopment and corrective dentofacial orthopedics. Angle Orthod. 1980 07;50(3):147-64.

33. Bresolin D, Shapiro PA, Shapiro GG, Chapko MK, Dassel S. Mouth breathing in allergic children: Its relationship to dentofacial development. Am J Orthod. 1983 04;83(4):334-40.

34. Cheng MC, Enlow DH, Papsidero M, Broadbent BH, J., Oyen O, Sabat M. Developmental effects of impaired breathing in the face of the growing child. Angle Orthod. 1988 10;58(4):309-20. 
35. Betts NJ, Vanarsdall RL, Barber HD, Higgins-Barber K, Fonseca RJ.

Diagnosis and treatment of transverse maxillary deficiency. Int $\mathrm{J}$ Adult Orthodon Orthognath Surg. 1995;10(2):75-96.

36. Allen D, Rebellato J, Sheats R, Ceron AM. Skeletal and dental contributions to posterior crossbites. Angle Orthod. 2003 10;73(5):515-24.

37. Kerr WJ, McWilliam JS, Linder-Aronson S. Mandibular form and position related to changed mode of breathing--a five-year longitudinal study. Angle Orthod. 1989 1989;59(2):91-6.

38. Oulis CJ, Vadiakas GP, Ekonomides J, Dratsa J. The effect of hypertrophic adenoids and tonsils on the development of posterior crossbite and oral habits. $\mathrm{J}$ Clin Pediatr Dent. 1994 1994;18(3):197-201.

39. Kopra DE, Davis EL. Prevalence of oral defects among neonatally intubated 3- to 5- and 7- to 10-year old children. Pediatr Dent. 1991 1991;13(6):349-55. 40. Adair SM, Milano M, Lorenzo I, Russell C. Effects of current and former pacifier use on the dentition of 24- to 59-month-old children. Pediatr Dent. 1995 1995;17(7):437-44.

41. Lindner A, Modéer T. Relation between sucking habits and dental characteristics in preschoolchildren with unilateral cross-bite. Scandinavian Journal of Dental Research. 1989 06;97(3):278-83.

42. Warren JJ, Bishara SE. Duration of nutritive and nonnutritive sucking behaviors and their effects on the dental arches in the primary dentition. Am J Orthod Dentofacial Orthop. 2002 04;121(4):347-56. 
43. Hesse KL, Artun J, Joondeph DR, Kennedy DB. Changes in condylar postition and occlusion associated with maxillary expansion for correction of functional unilateral posterior crossbite. Am J Orthod Dentofacial Orthop. 1997 04;111(4):410-8.

44. Paesani D, Westesson PL, Hatala MP, Tallents RH, Brooks SL. Accuracy of clinical diagnosis for TMJ internal derangement and arthrosis. Oral Surg Oral Med Oral Pathol. 1992 03;73(3):360-3.

45. Barghan S, Merrill R, Tetradis S. Cone beam computed tomography imaging in the evaluation of the temporomandibular joint. J Calif Dent Assoc. 2010 01;38(1):33-9.

46. Larheim TA. Current trends in temporomandibular joint imaging. Oral Surg Oral Med Oral Pathol Oral Radiol Endod. 1995 11;80(5):555-76.

47. Ahmad M, Hollender L, Anderson Q, Kartha K, Ohrbach R, Truelove EL, et al. Research diagnostic criteria for temporomandibular disorders (RDC/TMD): Development of image analysis criteria and examiner reliability for image analysis. ORAL SURG ORAL MED ORAL PATHOL ORAL RADIOL ENDO. 2009 06;107(6):844-60.

48. Larheim TA, Kolbenstvedt A. High-resolution computed tomography of the osseous temporomandibular joint. some normal and abnormal appearances. Acta Radiol Diagn (Stockh). 1984;25(6):465-9.

49. Tsiklakis K, Syriopoulos K, Stamatakis HC. Radiographic examination of the temporomandibular joint using cone beam computed tomography.

Dentomaxillofac Radiol. 2004 05;33(3):196-201. 
50. Hussain AM, Packota G, Major PW, Flores-Mir C. Role of different imaging modalities in assessment of temporomandibular joint erosions and osteophytes: A systematic review. Dentomaxillofac Radiol. 2008 02;37(2):63-71.

51. Honey OB, Scarge WC, Hilgers MJ, Klueber K, Silveira AM, Haskell BS, et al. Accuracy of cone-beam computed tomography imaging of the temporomandibular joint: Comparisons with panoramic radiology and linear tomography. Am J Orthod Dentofacial Orthop. 2007 10;132(4):429-38.

52. Zain-Alabdeen E, Alsadhan RI. A comparative study of accuracy of detection of surface osseous changes in the temporomandibular joint using multidetector CT and cone beam CT. Dentomaxillofac Radiol. 2012 03;41(3):185-91.

53. Ikeda K, Kawamura A. Assessment of optimal condylar position with limited cone-beam computed tomography. Am J Orthod Dentofacial Orthop. 2009 04;135(4):495-501.

54. Sergl HG, Farmland M. Experiments with unilateral bite planes in rabbits. Angle Orthod. 1975 04;45(2):108-14.

55. Kantomaa T, Pirttiniemi P. Differences in biologic response of the mandibular condyle to forward traction or opening of the mandible. an experimental study in the rat. Acta Odontol Scand. 1996 04;54(2):138-44.

56. Isotupa KP, Carlson DS, Mäkinen,K.K. Influence of asymmetric occlusal relationships and decreased maxillary width on the growth of the facial skeleton in the guinea pig. Ann Anat. 1992 10;174(5):447-51. 
57. Fuentes MA, Opperman LA, Buschang P, Bellinger LL, Carlson DS, Hinton RJ. Lateral functional shift of the mandible: Part II. effects on gene expression in condylar cartilage. Am J Orthod Dentofacial Orthop. 2003 02;123(2):160-6.

58. Liu C, Kaneko S, Soma K. Effects of a mandibular lateral shift on the condyle and mandibular bone in growing rats. Angle Orthod. 2007 09;77(5):787-93. 59. Troelstrup B, Møller E. Electromyography of the temporalis and masseter muscles in children with unilateral cross-bite. Scandinavian Journal of Dental Research. 1970 11;78(6):425-30.

60. Myers DR, Barenie JT, Bell RA, Williamson EH. Condylar position in children with functional posterior crossbites: Before and after crossbite correction. Pediatr Dent. 1980 09;2(3):190-4.

61. Nerder PH, Bakke M, Solow B. The functional shift of the mandible in unilateral posterior crossbite and the adaptation of the temporomandibular joints: A pilot study. Eur J Orthod. 1999 04;21(2):155-66.

62. Mongini $F$. The importance of radiography in the diagnosis of TMJ dysfunctions. A comparative evaluation of transcranial radiographs and serial tomography. J Prosthet Dent. 1981 02;45(2):186-98.

63. Pinto AS, Buschang PH, Throckmorton GS, Chen P. Morphological and positional asymmetries of young children with functional unilateral posterior crossbite. Am J Orthod Dentofacial Orthop. 2001 11;120(5):513-20.

64. Kecik D, Kocadereli I, Saatci I. Evaluation of the treatment changes of functional posterior crossbite in the mixed dentition. Am J Orthod Dentofacial Orthop. 2007 02;131(2):202-15. 
65. Pellizoni SEP, Salioni MAC, Juliano Y, Guimarães AS, Alonso LG. Temporomandibular joint disc position and configuration in children with functional unilateral posterior crossbite: A magnetic resonance imaging evaluation. Am J Orthod Dentofacial Orthop. 2006 06;129(6):785-93.

66. Leonardi R, Caltabiano M, Cavallini C, Sicurezza E, Barbato E, Spampinato C, et al. Condyle fossa relationship associated with functional posterior crossbite, before and after rapid maxillary expansion. Angle Orthod. 2012 11;82(6):1040-6. 67. Baba R, Konno Y, Ueda K, Ikeda S. Comparison of flat-panel detector and image-intensifier detector for cone-beam CT. Computerized Medical Imaging \& Graphics. 2002 03/06;26(3):153.

68. Baba R, Ueda K, Okabe M. Using a flat-panel detector in high resolution cone beam CT for dental imaging. Dentomaxillofac Radiol. 2004 09;33(5):28590.

69. Moshiri M, Scarfe WC, Hilgers ML, Scheetz JP, Silveira AM, Farman AG. Accuracy of linear measurements from imaging plate and lateral cephalometric images derived from cone-beam computed tomography. Am J Orthod Dentofacial Orthop. 2007 10;132(4):550-6.

70. Periago DR, Scarfe WC, Moshiri M, Scheetz JP, Silveira AM, Farman AG. Linear accuracy and reliability of cone beam CT derived 3-dimensional images constructed using an orthodontic volumetric rendering program. Angle Orthod. 2008 05;78(3):387-95. 
71. Rustemeyer P, Streubühr U, Suttmoeller J. Low-dose dental computed tomography: Significant dose reduction without loss of image quality. Acta Radiol. 2004 12;45(8):847-53.

72. Healthcare Human Factors Group. Computed tomography radiation safety issues in ontario. Toronto, Canada: Centre for Global eHealth Innovation: University Health Network; 2006.

73. Scarfe WC, Farman AG, Sukovic P. Clinical applications of cone-beam computed tomography in dental practice. J Can Dent Assoc. 2006 02;72(1):7580.

74. Cho HJ. A three-dimensional cephalometric analysis. J Clin Orthod. 2009 04;43(4):235.

75. Suomalainen A, Vehmas T, Kortesniemi M, Robinson S, Peltola J. Accuracy of linear measurements using dental cone beam and conventional multislice computed tomography. Dentomaxillofac Radiol. 2008 01;37(1):10-7.

76. Kobayashi K, Shimoda S, Nakagawa Y, Yamamoto A. Accuracy in measurement of distance using limited cone-beam computerized tomography. Int J Oral Maxillofac Implants. 2004 03/20;19(2):228-31.

77. Honda K, Arai Y, Kashima M, Takano Y, Sawada K, Ejima K, et al. Evaluation of the usefulness of the limited cone-beam CT (3DX) in the assessment of the thickness of the roof of the glenoid fossa of the temporomandibular joint. Dentomaxillofac Radiol. 2004 11;33(6):391-5.

78. Rodrigues AF, Fraga MR, Vitral RWF. Computed tomography evaluation of the temporomandibular joint in class I malocclusion patients: Condylar symmetry 
and condyle-fossa relationship. Am J Orthod Dentofacial Orthop. 2009 08;136(2):192-8.

79. Rodrigues AF, Fraga MR, Vitral RWF. Computed tomography evaluation of the temporomandibular joint in class II division 1 and class III malocclusion patients: Condylar symmetry and condyle-fossa relationship. Am J Orthod Dentofacial Orthop. 2009 08;136(2):199-206.

80. Brin I, Ben-Bassat Y, Blustein Y, Ehrlich J, Hochman N, Marmary Y, et al. Skeletal and functional effects of treatment for unilateral posterior crossbite. Am J Orthod Dentofacial Orthop. 1996 02;109(2):173-9.

81. Vitral RWF, Telles CDS. Computed tomography evaluation of temporomandibular joint alterations in class II division 1 subdivision patients: Condylar symmetry. Am J Orthod Dentofacial Orthop. 2002 04;121(4):369-75. 82. Vitral RWF, Telles CdS, Fraga MR, de Oliveira, Roberto Sotto,Maior Fortes, Tanaka OM. Computed tomography evaluation of temporomandibular joint alterations in patients with class II division 1 subdivision malocclusions: Condylefossa relationship. Am J Orthod Dentofacial Orthop. 2004 07;126(1):48-52. 83. Christiansen EL, Thompson JR, Zimmerman G, Roberts D, Hasso AN, Hinshaw DB, J., et al. Computed tomography of condylar and articular disk positions within the temporomandibular joint. Oral Surg Oral Med Oral Pathol. 1987 12;64(6):757-6.

84. Hansson T, Oberg T, Carlsson GE, Kopp S. Thickness of the soft tissue layers and the articular disk in the temporomandibular joint. Acta Odontol Scand. 1977 05;35(2):77-83. 
85. Kinniburgh RD, Major PW, Nebbe B, West K, Glover KE. Osseous morphology and spatial relationships of the temporomandibular joint: Comparisons of normal and anterior disc positions. Angle Orthod. 2000 02;70(1):70-8.

86. Major PW, Kinniburgh RD, Nebbe B, Prasad NG, Glover KE. Tomographic assessment of temporomandibular joint osseous articular surface contour and spatial relationships associated with disc displacement and disc length. Am J Orthod Dentofacial Orthop. 2002 02;121(2):152-61.

87. Katsavrias EG, Halazonetis DJ. Condyle and fossa shape in class II and class III skeletal patterns: A morphometric tomographic study. Am J Orthod Dentofacial Orthop. 2005 09;128(3):337-46.

88. Lam PH, Sadowsky C, Omerza F. Mandibular asymmetry and condylar position in children with unilateral posterior crossbite. Am J Orthod Dentofacial Orthop. 1999 05;115(5):569-75.

89. Christiansen EL, Chan TT, Thompson JR, Hasso AN, Hinshaw DB, J., Kopp S. Computed tomography of the normal temporomandibular joint. Scand J Dent Res. 1987 12;95(6):499-50.

90. Cohlmia JT, Ghosh J, Sinha PK, Nanda RS, Currier GF. Tomographic assessment of temporomandibular joints in patients with malocclusion. Angle Orthod. 1996;66(1):27-35.

91. Kilic N, Kiki A, Oktay H. Condylar asymmetry in unilateral posterior crossbite patients. Am J Orthod Dentofacial Orthop. 2008 03;133(3):382-7. 
92. Wang MQ, He JJ, Li G, Widmalm SE. The effect of physiological nonbalanced occlusion on the thickness of the temporomandibular joint disc: A pilot autopsy study. J Prosthet Dent. 2008 02;99(2):148-52.

93. Yamada K, Tsuruta A, Hanada K, Hayashi T. Morphology of the articular eminence in temporomandibular joints and condylar bone change. J Oral Rehabil. 2004 05;31(5):438-44.

94. Masi M, Lederman HM, Yamashita HK, LA. Temporomandibular joint evaluation with magnetic resonance imaging in children with functional unilateral posterior crossbite, treated with rapid maxillary expansion. Am J Orthod Dentofacial Orthop. 2009 08;136(2):207-1.

95. Lippold C, Hoppe G, Moiseenko T, Ehmer U, Danesh G. Analysis of condylar differences in functional unilateral posterior crossbite during early treatment--a randomized clinical study. J Orofac Orthop. 2008 07;69(4):283-96. 


\section{Appendices}

\section{Appendix A:}

April 17, 2014

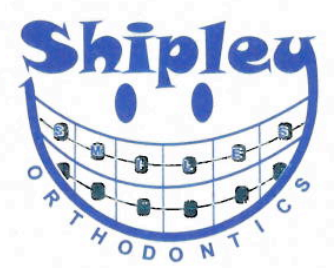

To Lance Pittman of WVU Orthodontics,

I, Dr. Thomas Shipley, authorize Lance Pittman and West Virginia University access to the patient health information, including the cone beam computed tomorgraphy images, at my private practice in Peoria, $\mathrm{AZ}$ to use to use in conducting the study "СBCT Evaluation of Condylar Changes in Children with Unilateral Posterior Crossbites with a Functional Shift."

The patient health information will include basic demographics, clinical exam findings, and the images.

Sincerely,

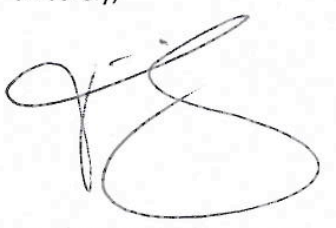

Dr. Thomas Shipley 


\section{Curriculum Vitae}

\section{EDUCATION:}

Institution

West Virginia University

West Virginia University

Fairmont State University

West Virginia University

Institute of Technology
Date $\quad$ Degree $\quad$ Major

2011- April

M.S.

Orthodontics

2014

2007- 2011

D.D.S

Dentistry

2005-2007

Biology

2004

Biology

\section{PROFESSIONAL EXPERIENCE}

\section{Dental Experiences}

- Rural Externship with Dr. Tom Leslie, Berkley Springs, WV. 2011

- Rural private practice experience including comprehensive dental care, patient management, and office management responsibilities.

- Externship at Parker Indian Hospital, Indian Health Service. 2010

- Performed dental services for the Native Americans of the Colorado River Indian Tribes.

- "Mission of Mercy" Dental Clinic, Eastern Panhandle of WV. 2009

- Student organizer that managed and allocated dental students station rotations, performed dental services, and aided in most aspects of the clinic operation.

RESEARCH EXPERIENCE/PRESENTATIONS: 
- Thesis currently under direction of Drs. Richard Jurevic and Peter Ngan

- "CBCT Evaluation of Condylar Changes in Children with Unilateral Posterior Crossbites with a Functional Shift".

- "Airway Analysis of Class I, II, and III Patients with Normodivergent, Hypodivergent, and Hyperdivergent Mandibular Planes Using 3D Cone Beam Computed Tomography."

- Dr. Peter Ngan Principal Investigator

- Poster presentation at West Virginia Dental Association $104^{\text {th }}$ Annual Session at White Sulphur Springs, WV. 2010

- Poster presentation at Alumni Day Research Convention in Morgantown, WV. 2010

\section{PROFESSIONAL AFFILIATIONS AND EXTRACURRICULAR ACTIVITIES:}

- Member, West Virginia Dental Association, ADA, and AAO. 2011Present 